\title{
Final Report for the Erosion and Corrosion Analysis of Waste Transfer Primary Pipeline Sections from 241-SY Tank Farm
}

\author{
J. S. Page \\ R. B. Wyrwas \\ G. A. Cooke \\ Washington River Protection Solutions LLC
}

Date Published

September 2012

Prepared for the U.S. Department of Energy

Office of River Protection

Contract No. DE-AC27-08RV14800 


\section{LAB-RPT-12-00007 R0}

\section{Executive Summary}

Three sections of primary transfer pipeline removed from the 241-SY Tank Farm in Hanford's 200 West area, labeled as SN-285, SN-286, and SN-278, were analyzed for the presence and amount of corrosion and erosion on the inside surface of the transfer pipe. All three sections of pipe, ranging in length between 6 and 8 in., were received at the 222-S Laboratory still in the pipe-in-pipe assembly. The annular spaces were filled with urethane foam injected into the pipes for as low as reasonably achievable (ALARA) purposes. The 3-in. primary transfer pipes were first separated from the outer encasement, 6-in. pipes. The pipes were cut into small sections, or coupons, based upon the results of a non-destructive pipe wall thickness measurement which used an ultrasonic transducer. Following removal of the foam, the coupons were subjected to a series of analytical methods utilizing both optical microscopy and scanning electron microscopy to obtain erosion and corrosion information.

The ultrasonic transducer analysis of the $\mathrm{SN}-285$ primary pipe did not show any thinned locations in the pipe wall which were outside the expected range for the 3 -in. schedule 40 pipe of 216 mils. A coupon was cut from the thinnest area on the pipe, and analysis of the inside surface, which was in contact with the tank waste, revealed a continuous layer of corrosion $\sim 100$ $\mu \mathrm{m}$ (4 mils) thick under a semi-continuous layer of tank waste residue $\sim 20 \mu \mathrm{m}$ (1 mil) thick. This residue layer was composed of an amorphous phase rich in chromium, magnesium, calcium, and chlorine. Small pits were detected throughout the inside pipe surface with depths up to $\sim 50 \mu \mathrm{m}(2 \mathrm{mils})$.

Similarly, the SN-286 primary pipe did not show, by the ultrasonic transducer measurements, any thinned locations in the pipe wall which were outside the expected range for this pipe. Analysis of the coupon cut from the pipe section showed the presence of a tank waste layer containing sodium aluminate and phases rich in iron, calcium, and chromium. This layer was removed by a cleaning process that left a pipe surface continuous in iron oxide/hydroxide (corrosion) with pockets of aluminum oxide, possibly gibbsite. The corrosion layer was $\sim 50 \mu \mathrm{m}$ ( 2 mil) thick over non-continuous pits less than $\sim 50 \mu \mathrm{m}$ deep ( 2 mils). Small particles of aluminum oxide were also detected under the corrosion layer.

The ultrasonic transducer analysis of SN-278, like the previous primary pipes, did not reveal any noticeable thinning of the pipe wall. Analysis of the coupon cut from the pipe showed that the inside surface had a layer of tank waste residue that was partially detached from the pipe wall. This layer was easily scraped from the surface and was composed of two separate layers. The underlying layer was $\sim 350 \mu \mathrm{m}$ ( 14 mils) thick and composed of a cementation of small aluminum oxide (probably gibbsite) particles. A thinner layer on top of the aluminum oxide layer was rich in carbon and chlorine. Scattered pitting was observed on the inside pipe surface with one pit as deep as $200 \mu \mathrm{m}$ ( 8 mils). 


\section{LAB-RPT-12-00007 R0}

\section{Table of Contents}

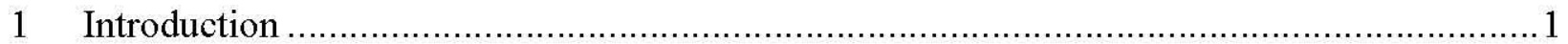

2 Sample Unpacking and Foam Removal ................................................................. 1

3 Obtaining Ultrasonic Testing Thickness Measurements ...............................................5

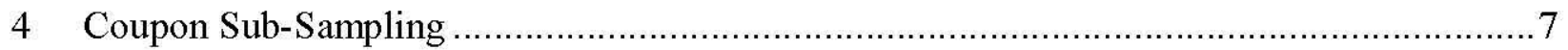

5 SN-285 Erosion and Corrosion Results .................................................................... 8

$5.1 \quad$ Ultrasonic Testing Thickness Measurement ..........................................................

5.2 Microphotography of the Inside Surface ..............................................................

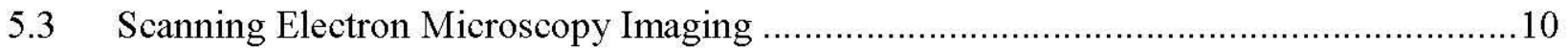

5.3.1 Scanning Electron Microscopy Imaging of Pipe Scrapings ...............................10

5.3.2 Scanning Electron Microscopy Imaging of the Inner Pipe Surface.......................14

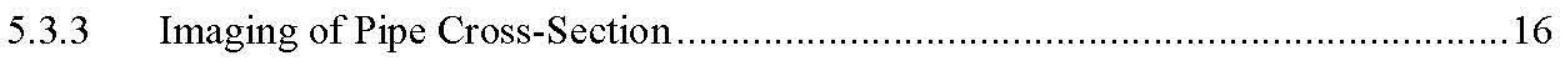

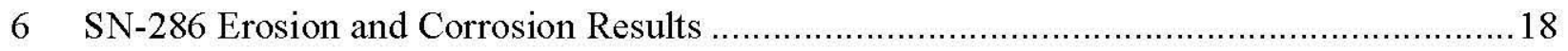

6.1 Ultrasonic Testing Thickness Measurement .......................................................... 18

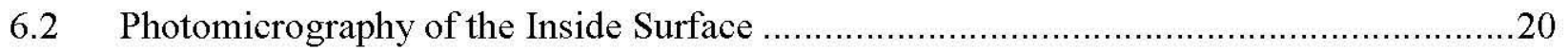

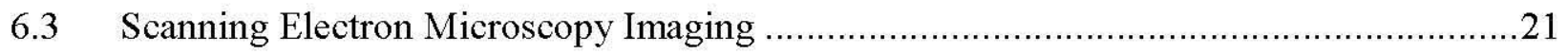

6.3.1 Scanning Electron Microscopy Imaging of Pipe Scrapings ............................21

6.3.2 Scanning Electron Microscopy Imaging of the Inner Pipe Surface......................24

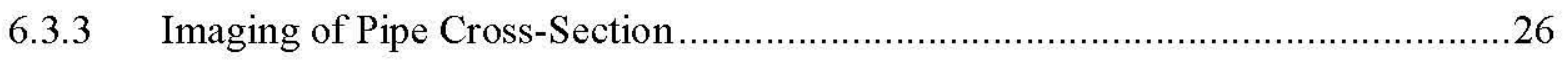

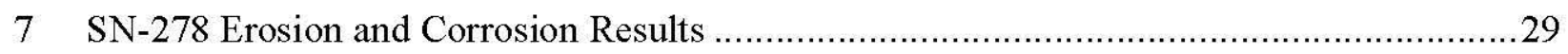

$7.1 \quad$ Ultrasonic Testing Thickness Measurement.......................................................29

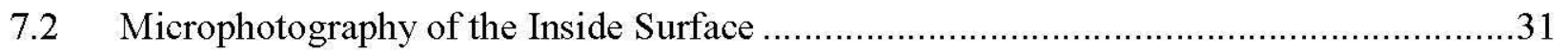

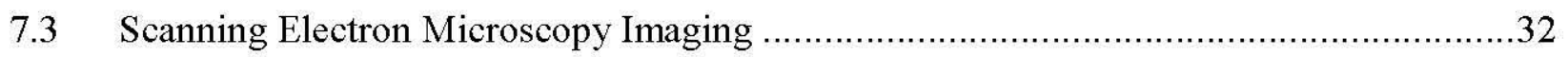

7.3.1 Scanning Electron Microscopy Imaging of Pipe Scrapings ................................32

7.3.2 Scanning Electron Microscopy Imaging of the Inner Pipe Surface.......................35

7.3.3 Imaging of Pipe Cross-Section ............................................................... 38

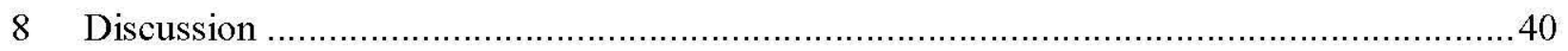

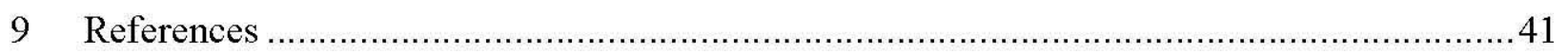

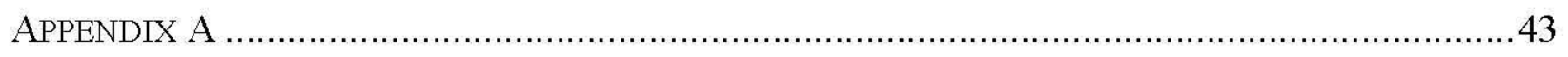

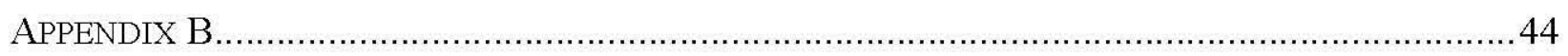




\section{LAB-RPT-12-00007 R0}

\section{List of Tables}

Table 1. Ultrasonic Testing Thickness Measurement Results for SN-285 Pipe Section. ............8

Table 2. Ultrasonic Testing Thickness Measurement Results for SN-286 Pipe Section. ...........19

Table 3. Ultrasonic Testing Thickness Measurement Results for SN-278 Pipe Section. ............30

\section{List of Figures}

Figure 1. Photograph of the SN-278 Pipe-in-Pipe Section during Sample Unpacking. ..............2

Figure 2. Photograph of the SN-278 Primary Pipe after Removal from the Pipe-in-Pipe

Assembly.

Figure 3. Photographs of the Cleaned Primary Pipes for Pipe Sections SN-285, SN-286, and SN278.

Figure 4. Photograph of SN-285 Pipe Section after the Final Cleaning Step. ..........................4

Figure 5. Photograph of the Calibration Block ...............................................................

Figure 6. Photograph of Acquiring Thickness Measurements Using an Ultrasonic Testing

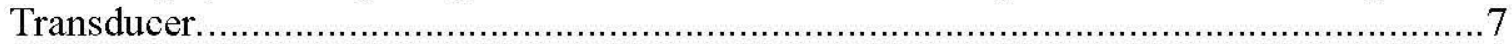

Figure 7. Photographs of the Coupon Cut from SN-285 Before and After Cleaning................9

Figure 8. Microphotographs of a Subsection of the SN-285 Coupon.....................................10

Figure 9. Scanning Electron Microscopy Image of Particles Scraped from the Inside Surface of

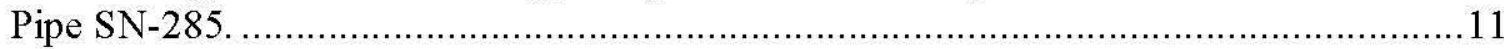

Figure 10. Scanning Electron Microscopy Image and Energy Dispersive Spectrometry Spectra of Aggregated Particles in the SN-285 Scrapings. ....................................................12

Figure 11. Scanning Electron Microscopy Image and Energy Dispersive Spectrometry Spectrum of Metal Shavings in the SN-285 Pipe Scrapings. .............................................. 13

Figure 12. Scanning Electron Microscopy Image and Energy Dispersive Spectrometry Spectrum of Foam Particles in the SN-285 Pipe Scrapings. ................................................... 13

Figure 13. Scanning Electron Microscopy Image and Energy Dispersive Spectrometry Spectra

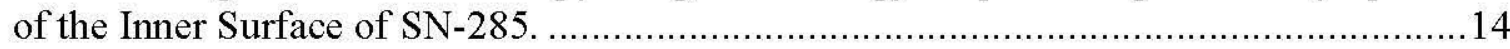

Figure 14. Secondary Electron Imaging and Backscatter Electron Imaging of the Inner Surface

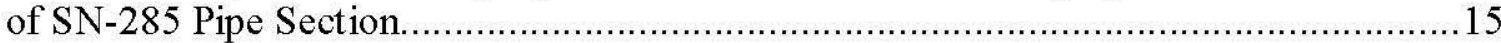

Figure 15. Microphotographs of Cross-Sectioned Specimen from SN-285 .........................16

Figure 16. Scanning Electron Microscopy Image and Energy Dispersive Spectrometry Spectra

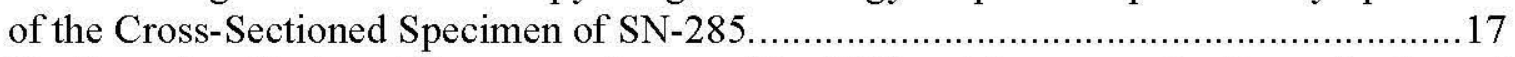

Figure 17. Scanning Electron Microscopy Image of the Different Layers on the Cross-Section of

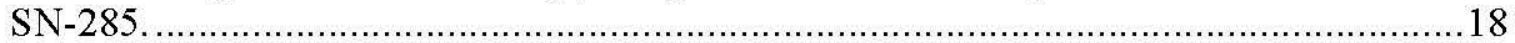

Figure 18. Photographs of the SN-286 Coupon Before and After Cleaning..........................20

Figure 19. Photomicrographs of a Subsection of the SN-286 Coupon....................................20

Figure 20. Scanning Electron Microscopy Image of a General Area on the Pipe Scraping

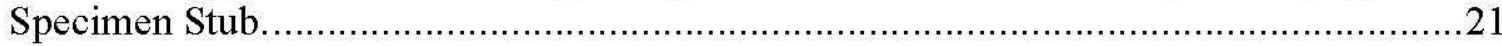

Figure 21. Scanning Electron Microscopy Image and Energy Dispersive Spectrometry Spectrum of a Corrosion Particle Scraped from the Inner Surface of SN-286...........................22

Figure 22. Scanning Electron Microscopy Image and Energy Dispersive Spectrometry Spectrum of Tank Waste Particles Scraped from SN-286......................................................23

Figure 23. Scanning Electron Microscopy Image and Energy Dispersive Spectrometry Spectrum of the Majority of the Particulate in the Pipe Scrapings of SN-286. 


\section{LAB-RPT-12-00007 R0}

Figure 24. Scanning Electron Microscopy Image and Energy Dispersive Spectrometry Spectrum of the Inner Wall of Pipe Section SN-286.

Figure 25. Scanning Electron Microscopy Image and Energy Dispersive Spectrometry Spectrum

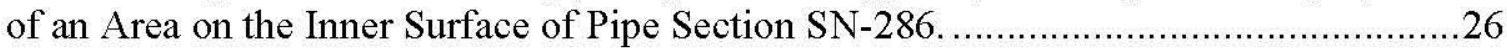

Figure 26. Photomicrographs of Cross-Sectioned Specimen from SN-286........................27

Figure 27. Scanning Electron Microscopy Image and Energy Dispersive Spectrometry Spectra

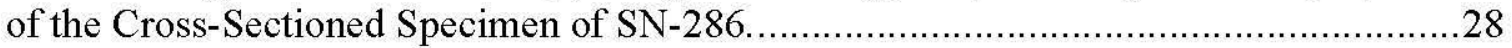

Figure 28. Scanning Electron Microscopy Image and Energy Dispersive Spectrometry Spectrum of the Corrosion Layer on SN-286 Inner Pipe. ............................................................29

Figure 29. Photographs of the SN-278 Coupon Before and After Cleaning...........................31

Figure 30. Photomicrographs of a Subsection of the SN-278 Coupon..................................... 31

Figure 31. Scanning Electron Microscopy Image of a General Area on the SN-278 Pipe Scraping Specimen Stub.

Figure 32. Scanning Electron Microscopy Image and Energy Dispersive Spectrometry Spectrum of a Flake Scraped from the SN-278 Pipe Section.

Figure 33. Scanning Electron Microscopy Image and Energy Dispersive Spectrometry Spectrum

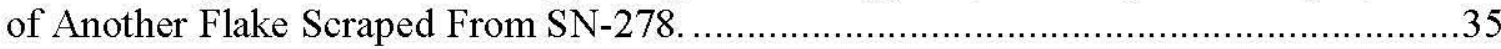

Figure 34. Scanning Electron Microscopy Image and Energy Dispersive Spectrometry Spectra of the Inner Wall of Pipe Section SN-278.

Figure 35. Scanning Electron Microscopy Image and Energy Dispersive Spectrometry Spectrum of Corrosion on the Exposed Grains of the Metal................................................... 37

Figure 36. Scanning Electron Microscopy Image and Energy Dispersive Spectrometry Spectrum

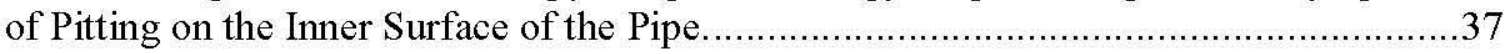

Figure 37. Photomicrographs of Cross-Sectioned Specimen from SN-278.........................38

Figure 38. Scanning Electron Microscopy Image and Energy Dispersive Spectrometry Spectra

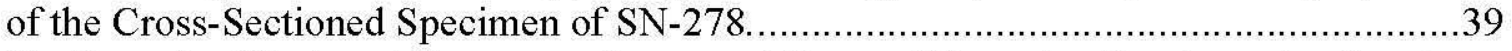

Figure 39. Scanning Electron Microscopy Image and Energy Dispersive Spectrometry Spectrum of the Carbon and Chlorine-Rich Layer on the Cross-Sectioned Coupon of SN-278......40 


\section{LAB-RPT-12-00007 R0}

\section{Abbreviations}

\section{List of Terms}

ALARA
BEI
EDS
NDE
SAS
SEI
SEM
UT

As Low As Reasonably Achievable Backscattered Electron Imaging Energy Dispersive Spectroscopy Non-Destructive Examination Special Analytical Services Secondary Electron Imaging Scanning Electron Microscopy

Units

in.

Inches

$\mathrm{mm}$

Millimeters

Micrometers

Thousandth of inch 


\section{LAB-RPT-12-00007 R0}

\section{INTRODUCTION}

This document is the final report summarizing the results of the examination of three sections of primary, carbon steel, transfer pipeline, labeled as SN-285, SN-286, and SN-278, which were located at the 241-SY Tank Farm in Hanford's 200 West Area. The analysis of these pipe sections was carried out as described in the approved 222-S Laboratory test plan, LAB-PLN-10-00015, Test Plan and Procedure for the Corrosion Analysis of Pipeline Sections from Hanford Tank Farms. This analysis was similar to previous transfer pipeline analyses performed by the Special Analytical Services group (SAS), LAB-RPT-11-00006, Final Report for the Corrosion Analysis of SN-285 and SN-286 Pipeline from SY Tank Farm, and Interoffice Memo 7S110-GAC-05-035, "Final Analytical Results from the Examination of Corrosion on Sections of 244AR Cross-Site Transfer Pipe." However, in these previous studies, the main focus was to examine the outer, encasement pipe and the annular space.

This current analysis was directed at the inner surface of the inside waste transfer pipe in order to document any erosion and corrosion caused by the in-field use of these primary pipes in the transfer of tank waste. This information supports the development of future corrosion allowances for the primary piping as part of the Washington River Protection Solution, LLC. fitness-for-service program.

This final report summarizes the results of this examination by providing photographs, photomicrographs, ultrasonic transducer (UT) thickness measurements, digital caliper thickness measurements, scanning electron microscopy (SEM) images, energy dispersive spectroscopy (EDS) spectra, and data tables acquired during the execution of the test plan by SAS.

Photographs provide visual documentation of the progression of the analysis and an overall view of the tank waste residues and corrosion inside the transfer pipes and pipe sections (coupons) cut from the pipes. Photomicrographs provide magnified views of the coupons and areas of interest on the surface. The SEM analyses afford increased magnification of the tank waste residues, corrosion, pitting, and elemental identification of these phases. Data tables summarize the UT thickness measurements recorded in 1-in. grid patterns across the entire pipe sections.

\section{SAMPLE UNPACKING AND FOAM REMOVAL}

The 3-in. diameter, schedule 40 primary pipe sections of SN-285 (OmniLIMS sample number S11R000083) and SN-286 (sample number S11R000085) were removed from the 6-in., schedule 40 outer pipe (pipe-in-pipe) assembly during a previous study which analyzed the level of corrosion on the outer pipes, and these details can be found in the final report (LAB-RPT-11-00006). The 3-in. diameter, schedule 40 inner primary pipe of the sectioned SN-278 (sample number S11R000257) was removed from the pipe-in-pipe assembly during the current analysis. The SN-278 pipe section arrived from the tank farm packaged in a layer of rubber matting and plastic bags. Figure 1 shows the pipe section partially removed from the 


\section{LAB-RPT-12-00007 R0}

rubber matting. The pipeline was filled with urethane foam (Handi-Foam ${ }^{\circledR 1}$ Quick Cure II-205) before cutting to reduce the spread of radioactive contamination. This foam can be seen in Figure 1 along with metal shavings on the foam surface from the cut in the field.

Figure 1. Photograph of the SN-278 Pipe-in-Pipe Section during Sample Unpacking.

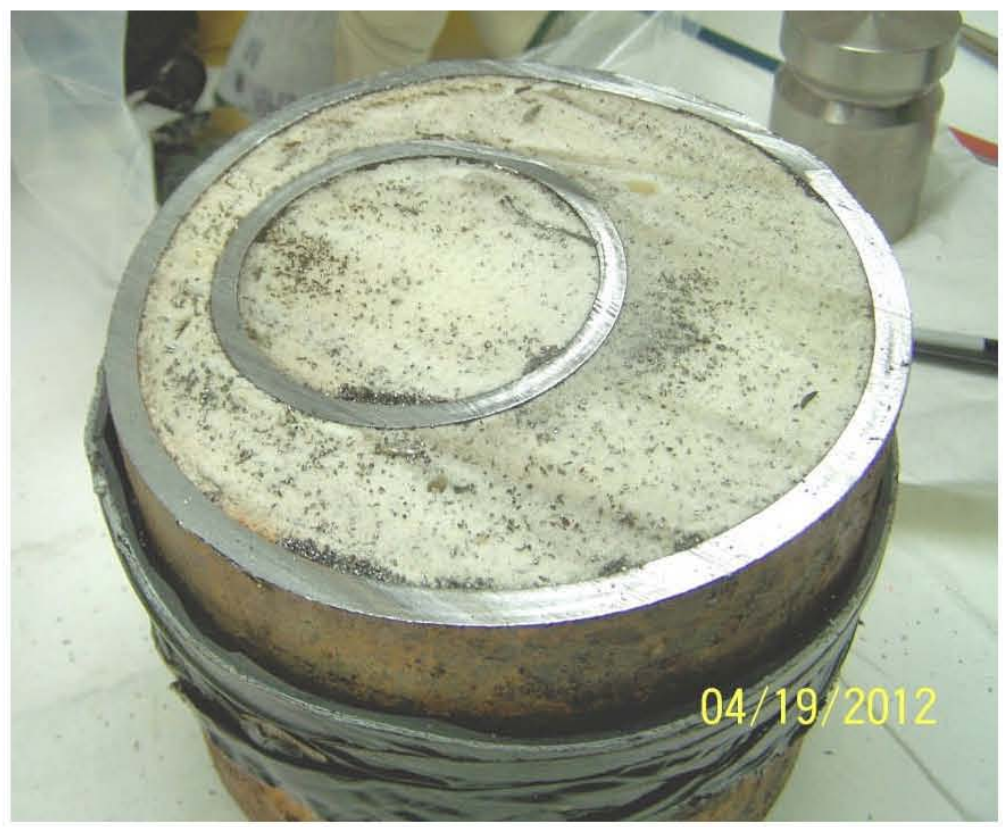

Similar to the SN-285 and SN-286 pipe section, the inner pipe of SN-278 had to be liberated from the pipe assembly. This separation was accomplished in a hood using a large screwdriver to remove chunks of foam until the inner pipe was free, see Figure 2. The metal lid end caps in the photo also held a layer of rubber matting for as low as reasonably achievable (ALARA) purposes.

${ }^{1}$ Handi-Foam is a registered trademark of Fomo Products, Inc., Norton, Ohio. 
Figure 2. Photograph of the SN-278 Primary Pipe after Removal from the Pipe-in-Pipe Assembly.

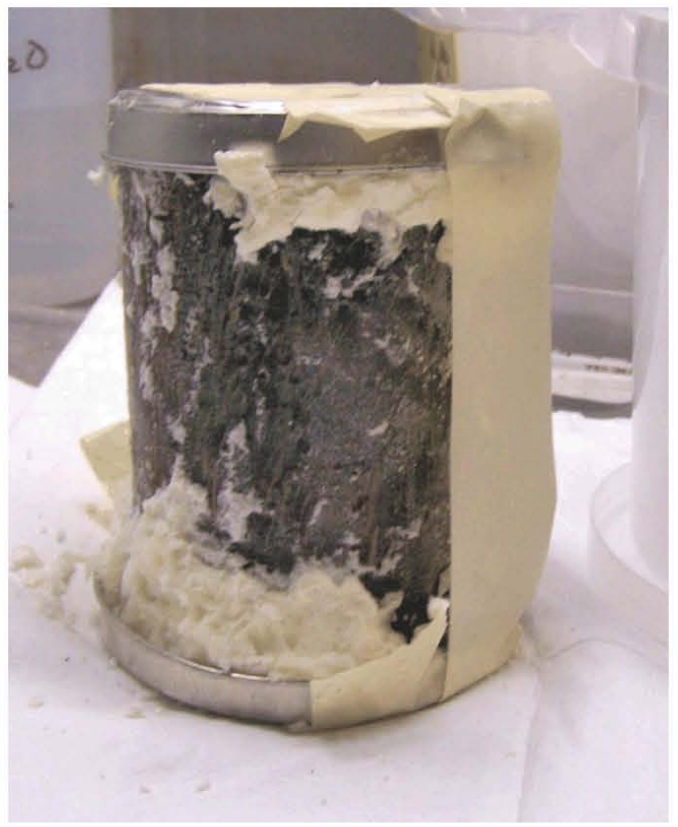

The remainder of the foam on all three pipe sections was removed mechanically, using forceps, and chemically, by applying acetone to soften the foam and gently scrubbing with a plastic bristle brush. Photographs of the three cleaned inner pipes are displayed in Figure 3 (SN-285, SN-286, and SN-278 from left to right).

Figure 3. Photographs of the Cleaned Primary Pipes for Pipe Sections SN-285, SN-286, and $\mathrm{SN}-278$.

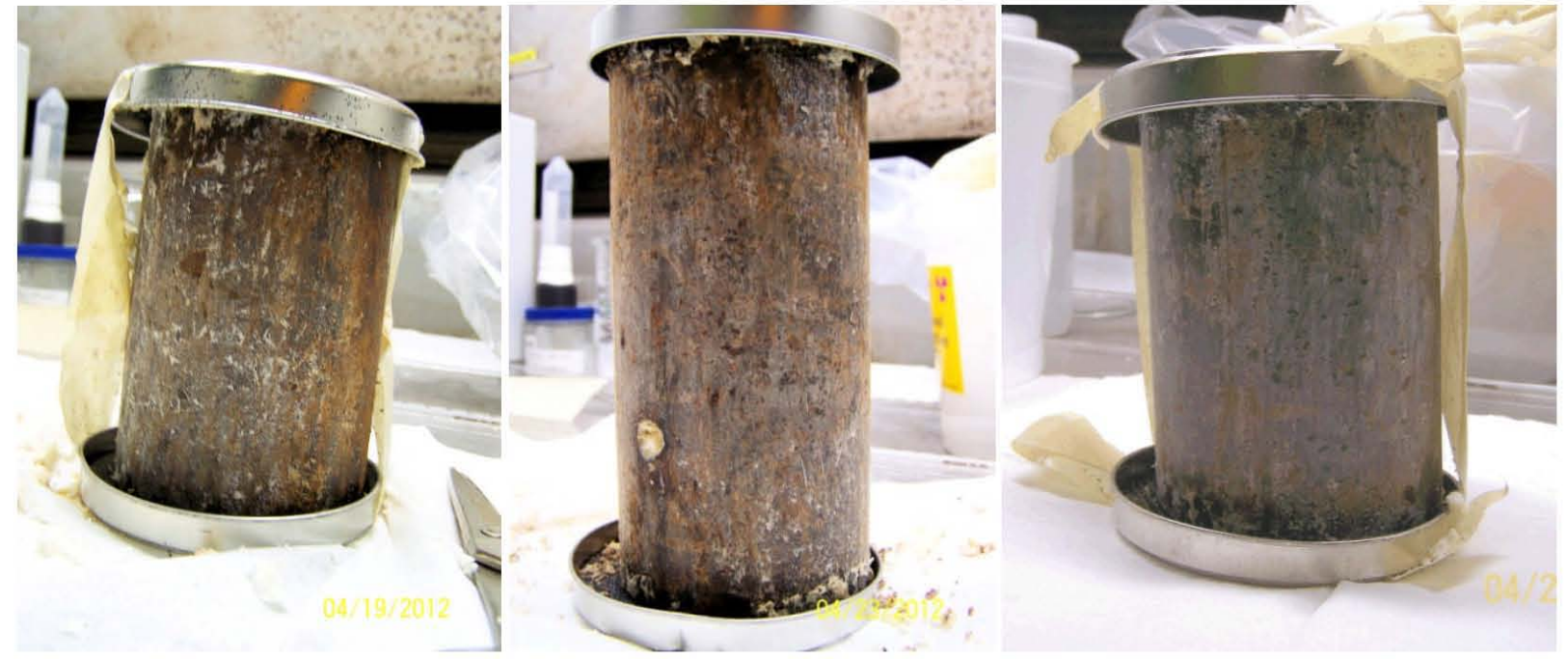




\section{LAB-RPT-12-00007 R0}

It is important to note that all three pipe sections contained a hole, as seen on SN-286 in Figure 3, which was used to inject the inner pipe with the foam, and this foam was still present in the pipe throughout the analysis until the coupons were cut from the pipe sections (the foam did not degrade the UT thickness measurements).

In preparation for the UT thickness measurements, non-destructive examination (NDE) certified engineers from AREVA Federal Services visited the 222-S Laboratory to see the pipe sections first-hand before performing the actual measurements. They verified that the sections should provide reliable UT data, and they suggested an additional outside surface cleaning step which included scrubbing with a very coarse steel wool to remove the small spots of foam and corrosion still present on the surface. This step was important so that the transducer would rest correctly on the surface for all measurements to ensure no false readings.

While in a hood, all three pipe sections were wetted with acetone and scrubbed with steel wool. The pipes were then wiped down with a wet paper towel and allowed to dry in the hood. This cleaning produced a smooth surface on all the sections. A photograph of the final, cleaned SN-285 pipe section is shown in Figure 4.

Figure 4. Photograph of SN-285 Pipe Section after the Final Cleaning Step.

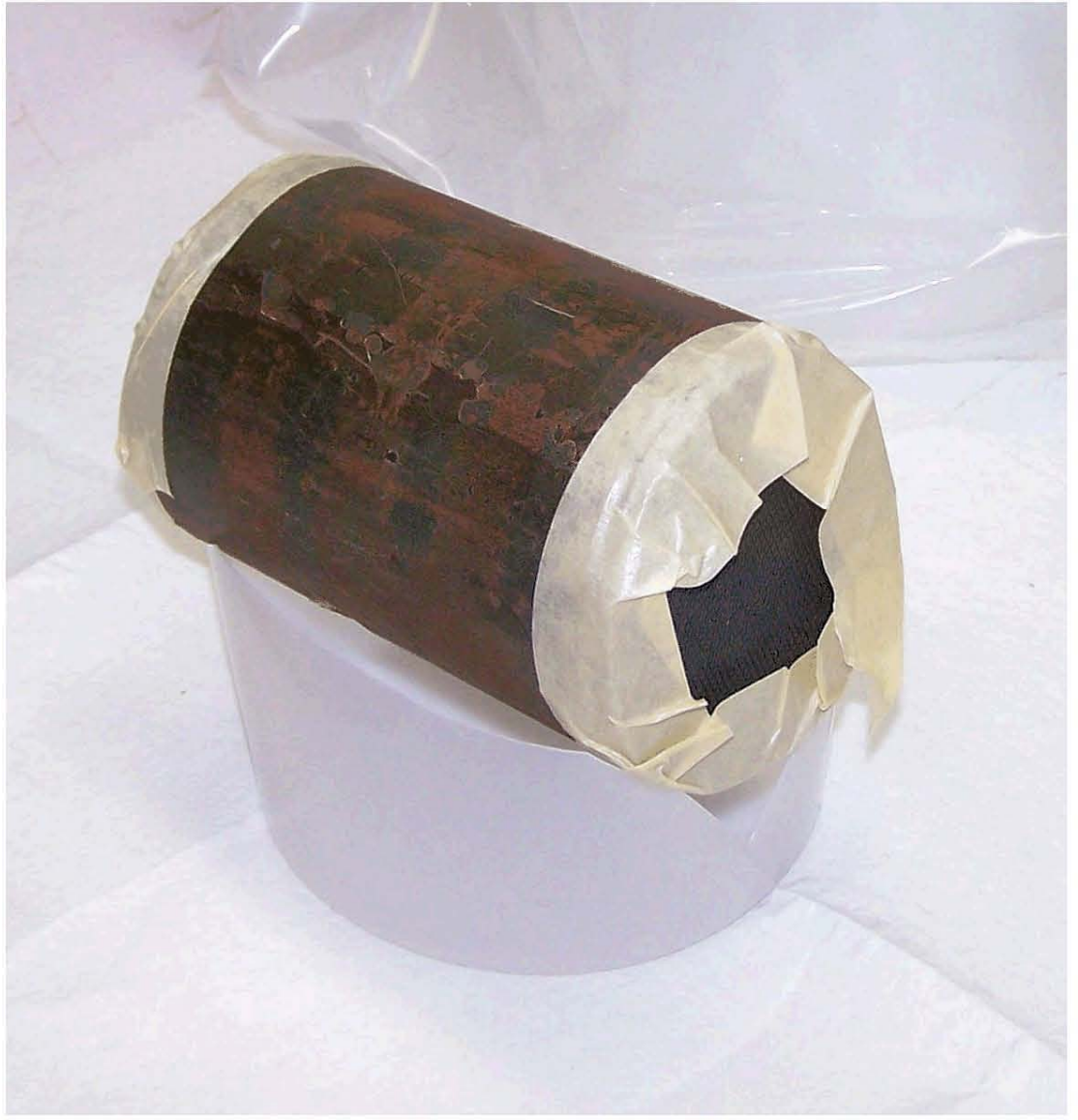




\section{OBTAINING ULTRASONIC TESTING THICKNESS MEASUREMENTS}

In order to gain pipe wall thicknesses across all three pipes, UT measurements were performed by NDE engineers from AREVA Federal Services. This process measured locations around the pipes in 1-in. increments to determine where any thin spots (which may have occurred due to either erosion of the inner wall by movement of abrasive tank waste or corrosion) might be located on the pipes. The results of the UT measurements provided guidance in determining the locations where coupons were cut from the pipe sections showing the greatest wear. The thickness of the coupons was also measured using digital calipers.

Use of a thickness reference standard or calibration block was central to the accuracy of the UT measurements. The calibration block used for these analyses was made from a schedule 40 pipe section milled to three different pipe wall thicknesses: 179, 196, and 221 mils. Figure 5 shows a photograph of the calibration block with gel couplant on the surface to ensure a proper contact with the metal. The calibration block was certified through Energy Northwest prior to use, and a copy of the calibration certificate is in Appendix A.

Figure 5. Photograph of the Calibration Block.

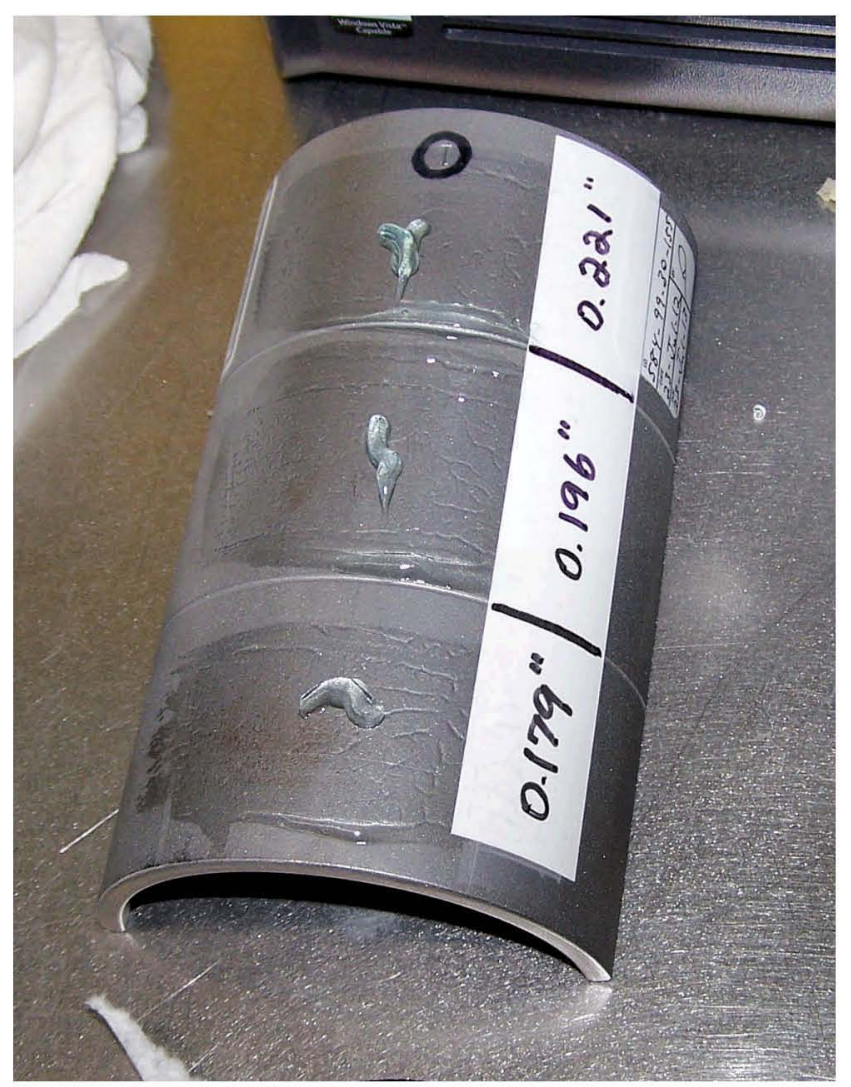




\section{LAB-RPT-12-00007 R0}

The calibration block was used to verify the accuracy of the transducer before (pre), and after (post) each series of data collection on each pipe. The results of the calibration block measurements are located on the second page of Appendix B.

In order to acquire thickness measurements, a plastic template was wrapped around the pipe and secured in place with rubber bands. The start location and direction of the template were

recorded on the pipe so the same locations could be obtained later. The template was a 1-in. grid with holes punched out allowing the spring-mounted transducer to snap in place once the center of each grid was located. The grid was labeled alpha numeric with $\mathrm{A}-\mathrm{K}$ running vertically on the flattened template and $1-6$ horizontally. When the template was wrapped around the pipes, the alphabetic numbers ran around the perimeter of the pipe and the numeric numbers ran down the pipe length. Figure 6 shows the template wrapped around one of the pipe sections during a series of measurements. The figure also shows the transducer located inside a saddle apparatus which helped in reproducibility in transducer contact to the pipe surfaces. After each series of measurements, three random points were chosen to be measured again to provide information on precision. In addition, the template was removed and the transducer was moved across the pipe surface while looking for both the lowest and highest readings to make sure a low or high spot was not overlooked by the 1-in. grid spacing. The results of these measurements are shown and discussed in the parts of this report detailing the individual pipe sections and in Appendix B. 
Figure 6. Photograph of Acquiring Thickness Measurements Using an Ultrasonic Testing Transducer.

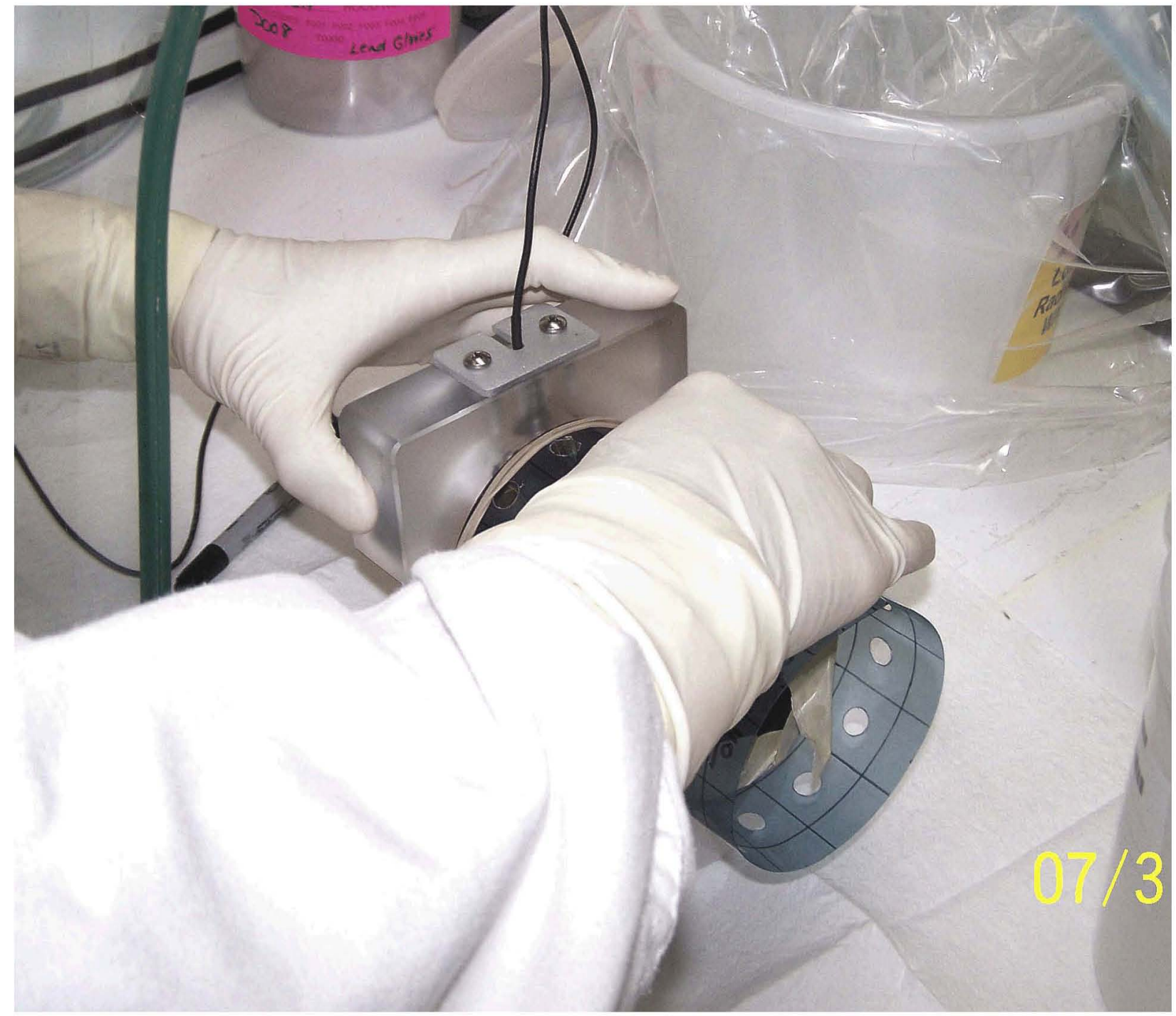

\section{COUPON SUB-SAMPLING}

The UT thickness results guided the location of where coupons were cut from the pipe sections. Using a red wax pencil, an area $\sim 2 \mathrm{X} 2 \mathrm{in}$. was marked on each pipe where the thinnest UT measurements were detected. The pipes were then loaded into a hot cell which housed a portable band saw. The band saw was used to isolate the area of the coupon on each pipe. The coupons were then loaded out of the hot cell for further analysis. 
LAB-RPT-12-00007 R0

\section{SN-285 EROSION AND CORROSION RESULTS}

\subsection{ULTRASONIC TESTING THICKNESS MEASUREMENT}

A copy of all the results from the UT thickness measurements can be found in Appendix B. The results, in inches for $\mathrm{SN}-285$, are transcribed in Table 1.

Table 1. Ultrasonic Testing Thickness Measurement Results for SN-285 Pipe Section.

\begin{tabular}{r|ccccc|}
$\begin{array}{c}\text { Alpha Numeric } \\
\text { Grid Labels }\end{array}$ & 1 & 2 & 3 & 4 & 5 \\
\hline A & $.219^{*}$ & .222 & .222 & .226 & .227 \\
B & .229 & .234 & .234 & .237 & .235 \\
C & .234 & .239 & .236 & .235 & .234 \\
D & .226 & .223 & .221 & .221 & .227 \\
E & .232 & .230 & .227 & .230 & .228 \\
F & .236 & .233 & .231 & .231 & .231 \\
G & .231 & .222 & .224 & .222 & .224 \\
H & .228 & .226 & .231 & .231 & $.23 A^{* *}$ \\
I & .235 & .234 & .238 & .235 & .232 \\
J & .219 & .220 & .219 & .219 & .213 \\
K & .221 & .222 & .227 & .224 & \\
\end{tabular}

* - All measurements are in inches.

** - Location of hole in the pipe; no measurement could be made.

--- - Dotted-line box indicates the approximate area where the coupon was cut.

Overall, there was no obvious low spot in this pipe section. The measurements show a relatively narrow spread in thicknesses, and the variation of thickness could be from the non-flat outer surface and variation in the pipe manufacturing. Based upon these results, a 2 X 2 in. coupon was cut around the J-5 location. The thickness of the coupon was measured with a digital caliper at 210 mils. This value corresponds with the thickness measurement using the UT, and it is close to schedule 40 pipe thickness (216 mils) indicating minimal, if any, erosion or corrosion in this section.

When the coupon was cut from the pipe section, a large piece of foam remained adhered to the surface. In order to obtain clear optical and SEM images of the inner surface of the pipe, the foam was removed by an acetone and water wash using a soft bristled plastic brush. Before this cleaning process, an exposed area on the coupon was scraped, and these scrapings were kept for SEM and EDS analyses. Photographs of the coupon both before (A) and after (B) the cleaning are shown in Figure 7. The area in the upper left corner of Fig. 7B was where the scrapings were obtained. 
Figure 7. Photographs of the Coupon Cut from SN-285 Before and After Cleaning.
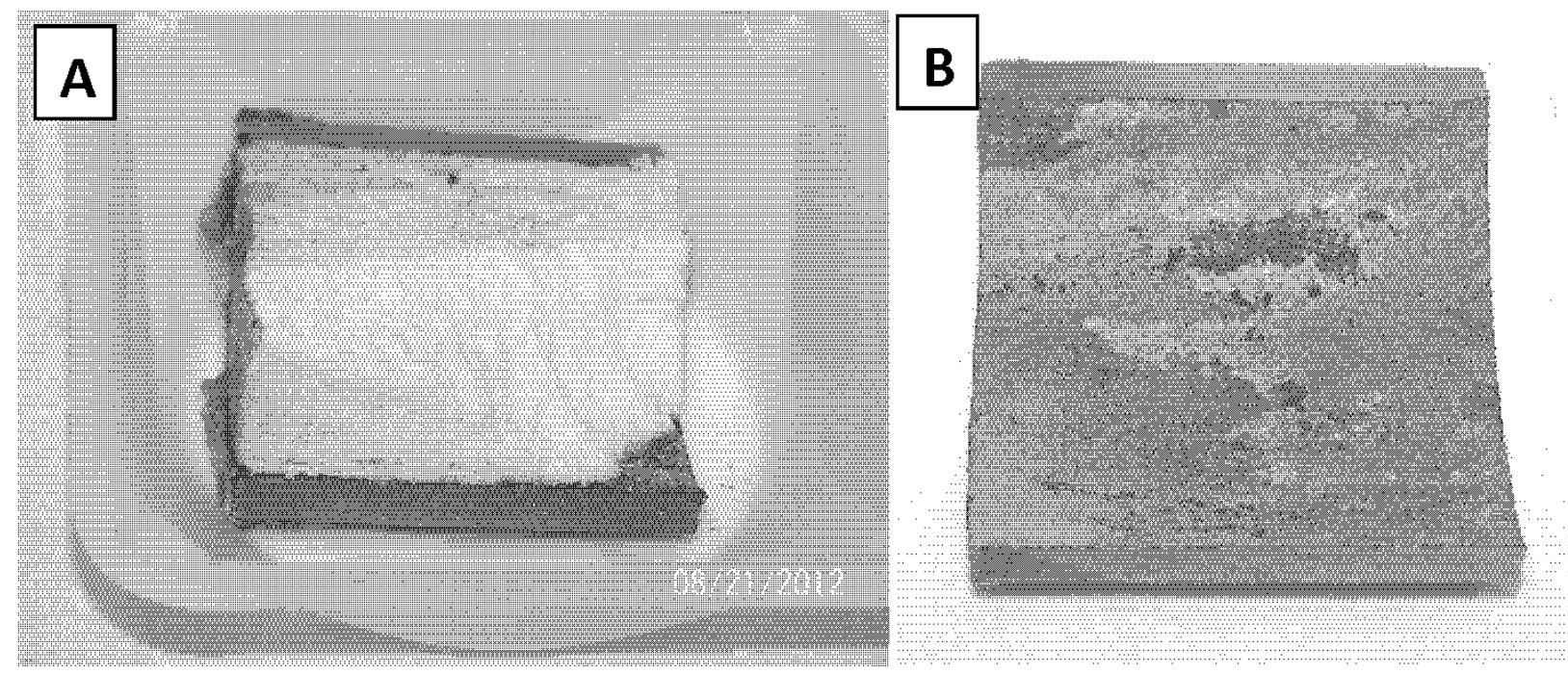

\subsection{MICROPHOTOGRAPHY OF THE INSIDE SURFACE}

A smaller piece of the pipe section was cut from the lower right hand area of the coupon in Figure 7B to fit in the SEM. Before being loaded in the SEM, photomicrographs were obtained using a Nikon $\mathbb{R}^{2}$ reflected light stereo microscope. Figure 8 shows the resulting photomicrographs at two different magnifications with $1 \mathrm{~mm}$ scale bars. The right image is a magnified area of the section in $8 \mathrm{~A}$ indicated by the yellow box. Overall, the surface appears free of particles with raised features which could be corroded steel. In addition, the variable colors suggest patches of tank waste residue and/or iron oxide/hydroxide. Running down the axis of the pipe are also small grooves covered by the corrosion and/or tank waste indicating that the grooves were not recently made.

\footnotetext{
${ }^{2}$ Nikon is a registered trademark of Nikon Corporation, Tokyo, Japan.
} 
Figure 8. Microphotographs of a Subsection of the SN-285 Coupon.

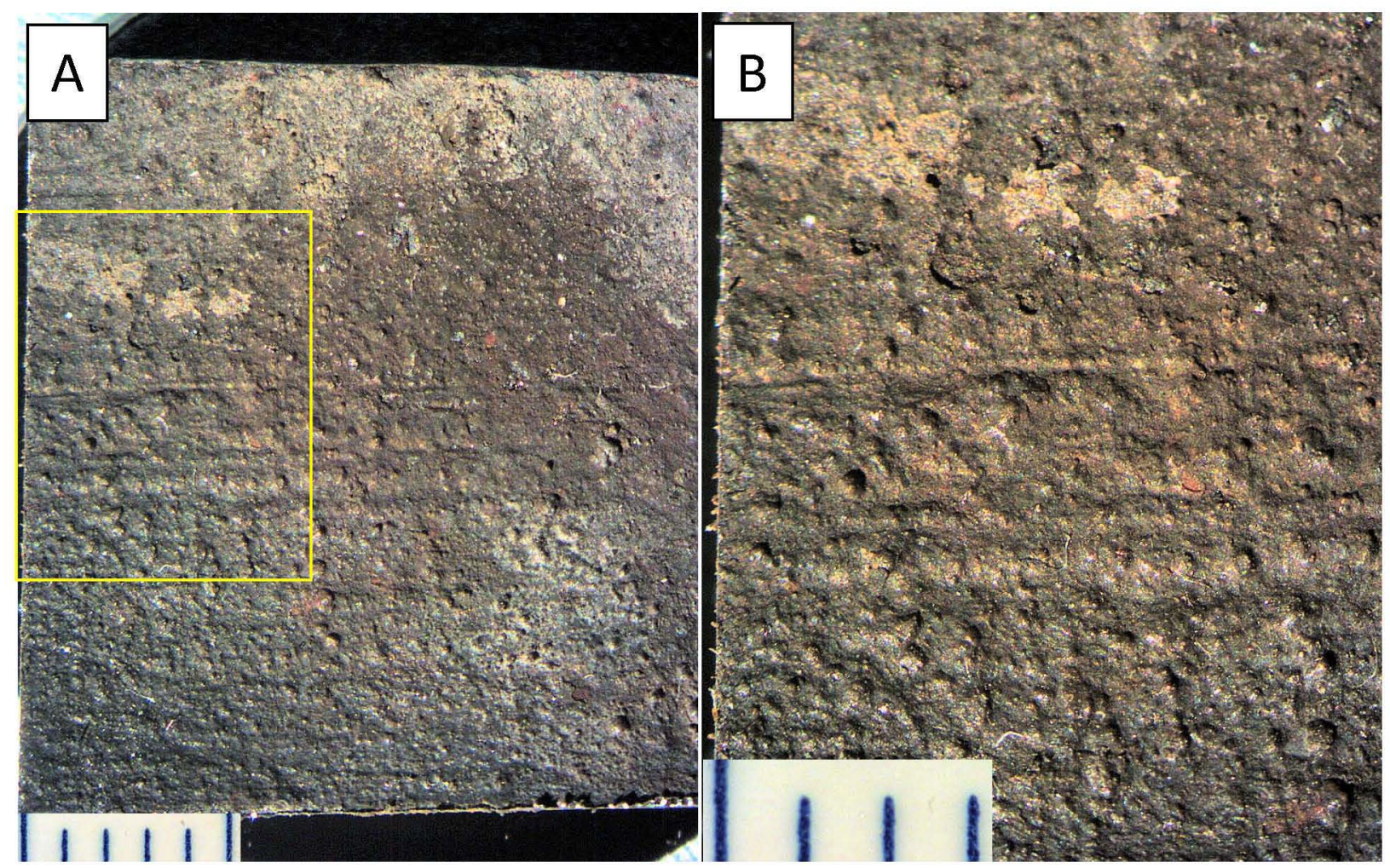

\subsection{SCANNING ELECTRON MICROSCOPY IMAGING}

Analysis by SEM was conducted in accordance with ATS-LT-161-100, "222-S Laboratory Sample Preparation and Operating Procedure for Scanning Electron Microscopes," using an Aspex $\circledR^{3}$ Personal Scanning Electron Microscope (PSEM), Model II, with a Noran light element EDS detector for chemical analysis. The instrument was operated at an accelerating voltage of $20 \mathrm{kV}$, and the samples were mounted at a working distance of 15 to $20 \mathrm{~mm}$. Images were acquired in secondary electron image (SEI) and backscatter electron image (BEI) modes. The EDS spectra were acquired for 30 seconds live time (unless noted).

\subsubsection{Scanning Electron Microscopy Imaging of Pipe Scrapings}

The pipe scrapings, detailed in Section 5.1, were prepared for SEM analysis by lifting them from a plastic weigh boat using a double-sided conductive, carbon adhesive sticker attached to a 1-in. stub. The specimen on the stub was then carbon coated using carbon vapor deposition.

Figure 9 shows a general area on the specimen stub and highlights the three main components found in the scrapings. These are identified by the three yellow boxes which refer to following figures in which the areas are shown under a higher magnification and with the subsequent

\footnotetext{
${ }^{3}$ ASPEX $®$ is a registered trademark of Aspex Corporation, Delmont, Pennsylvania.
} 


\section{LAB-RPT-12-00007 R0}

EDS analysis of the elemental composition of the particles. The three types of particles tended to be (1) tank waste associated sub particles and corrosion particles aggregated together and/or embedded in foam, (2) metal shavings from the cutting/scraping of the pipe, and (3) particles of foam.

Figure 9. Scanning Electron Microscopy Image of Particles Scraped from the Inside Surface of Pipe SN-285.

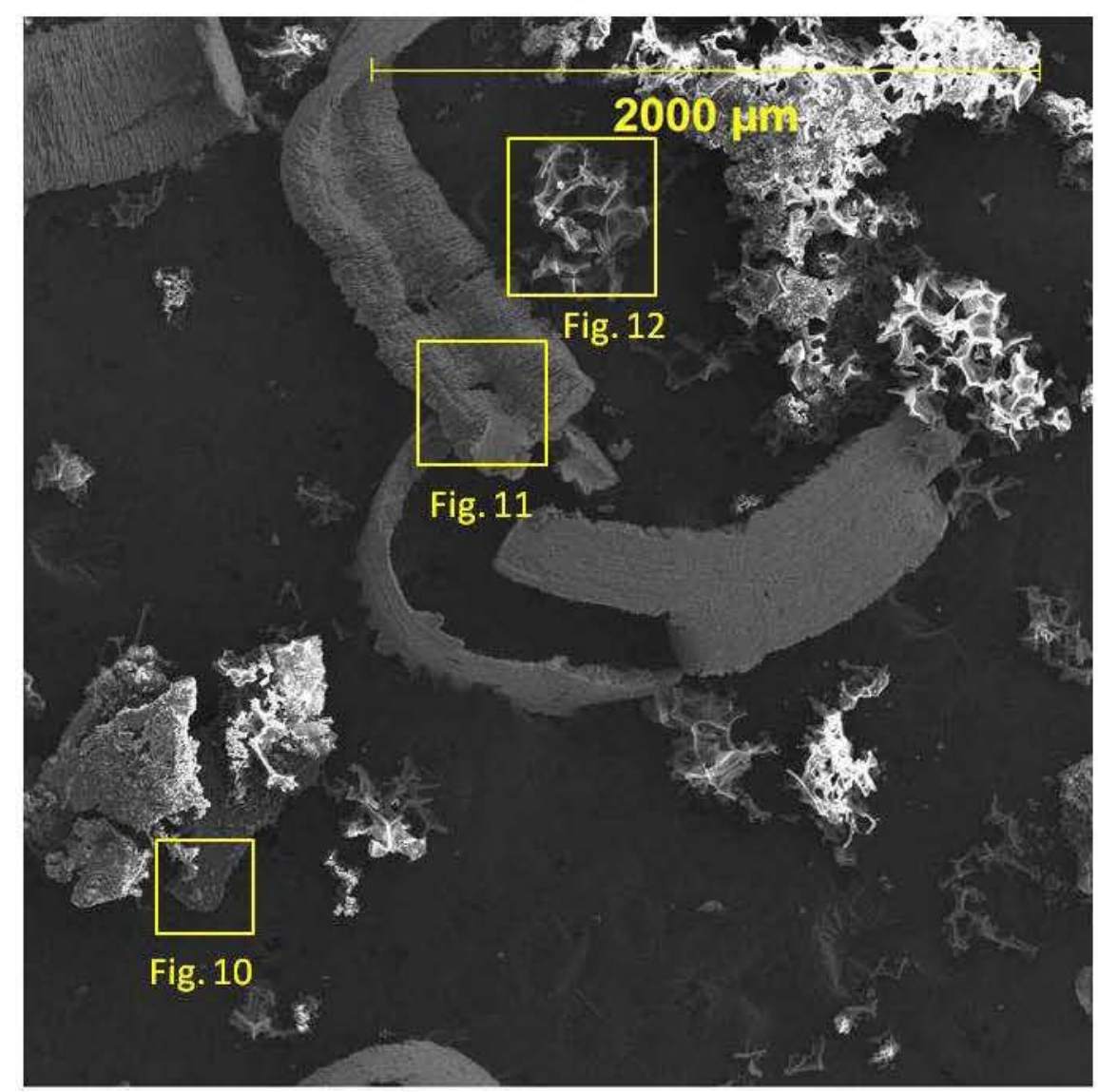

Figure 10 shows larger particles, such as iron oxide at point 2, embedded in a background matrix of aggregated smaller particles, point 1 , rich in silica, chloride, oxygen, titanium, aluminum, and magnesium. 
Figure 10. Scanning Electron Microscopy Image and Energy Dispersive Spectrometry Spectra of Aggregated Particles in the SN-285 Scrapings.
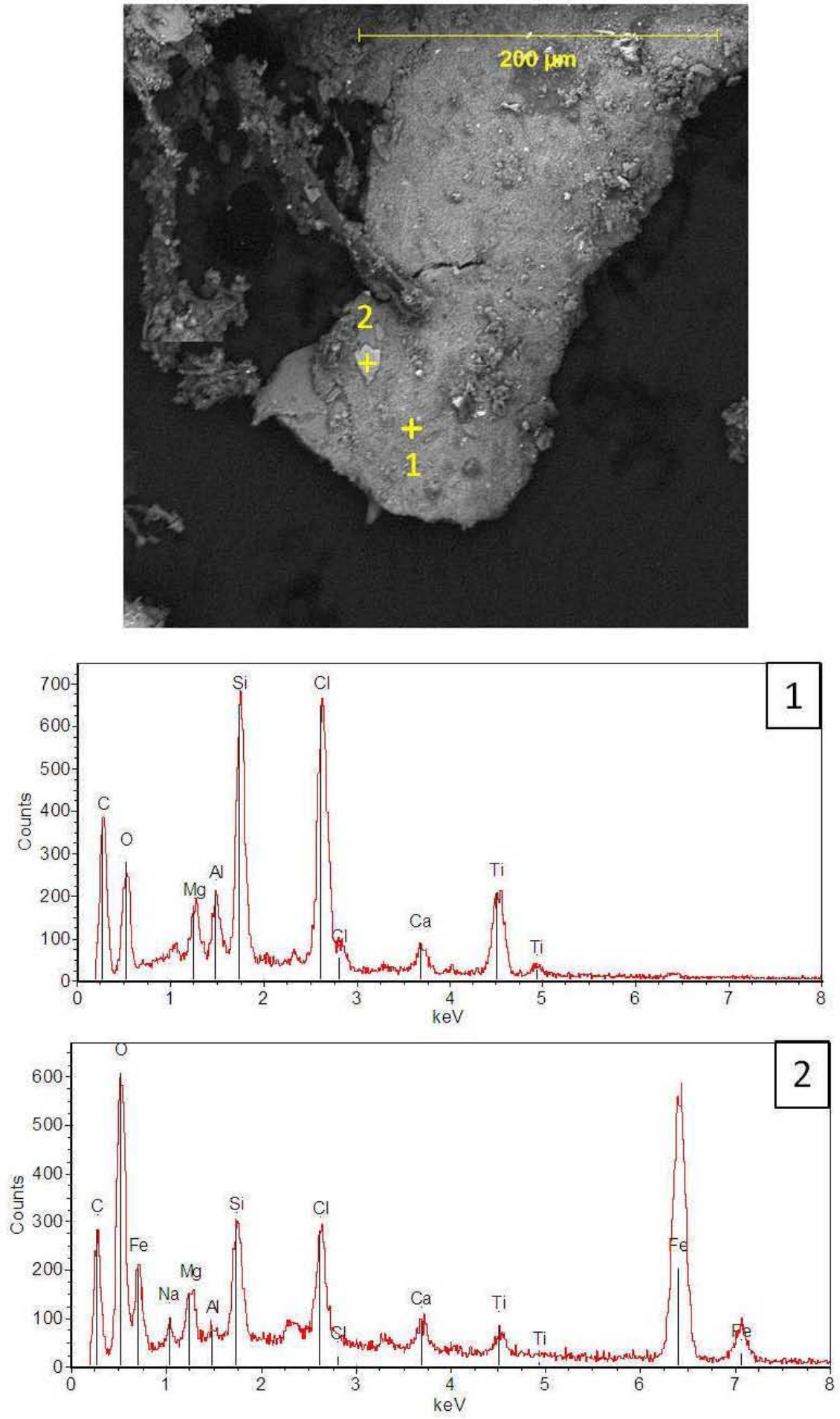

Figure 11 is an example of particles in the scrapings that were metal shavings from the cutting and scraping of the pipe, and Figure 12 shows that other particles were from the foam which was injected into the pipe for the in-field removal. In summary, most of the scrapings were not from 


\section{LAB-RPT-12-00007 R0}

residues on the inner surface of the pipe but were from the foaming and cutting processes. The bits of scrapings that did show an origin from the pipe surface mainly consisted of small particle aggregates, probably coming from the tank waste, and corrosion particles.

Figure 11. Scanning Electron Microscopy Image and Energy Dispersive Spectrometry Spectrum of Metal Shavings in the SN-285 Pipe Scrapings.
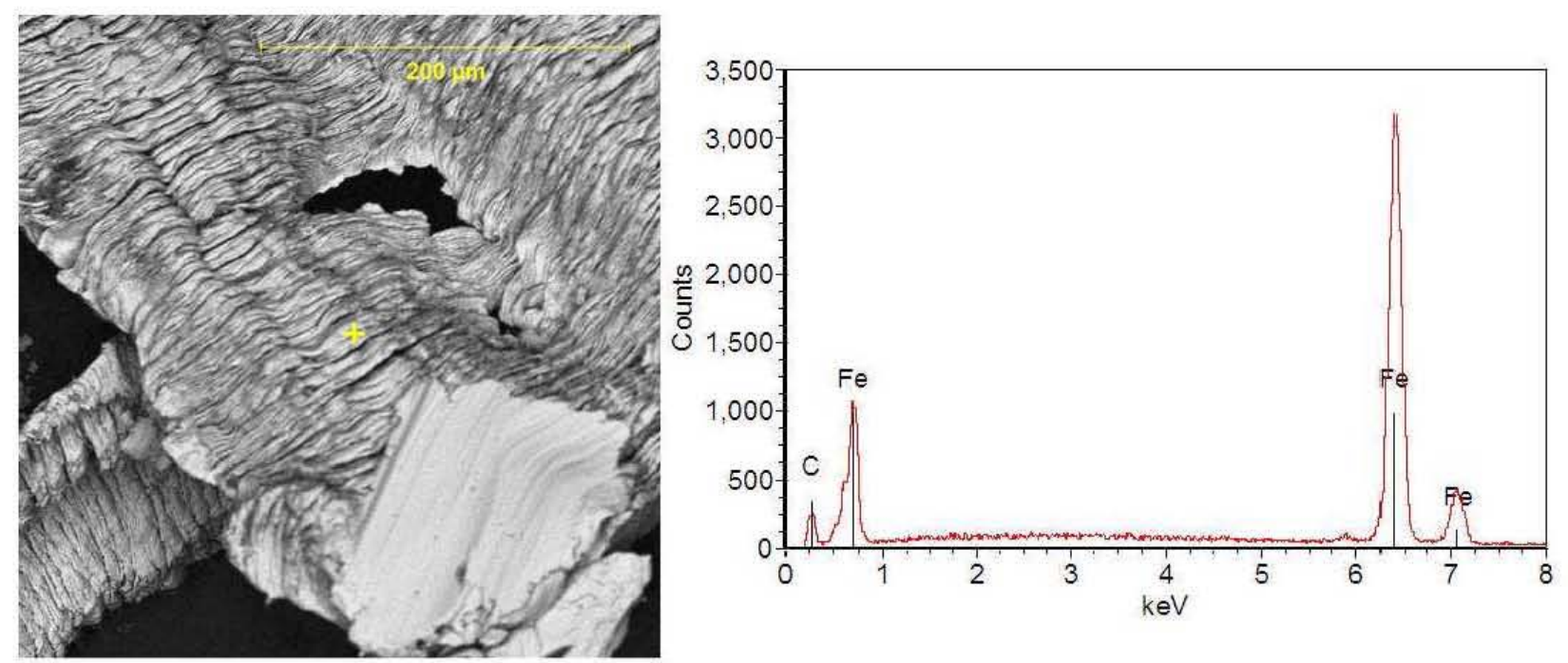

Figure 12. Scanning Electron Microscopy Image and Energy Dispersive Spectrometry Spectrum of Foam Particles in the SN-285 Pipe Scrapings.
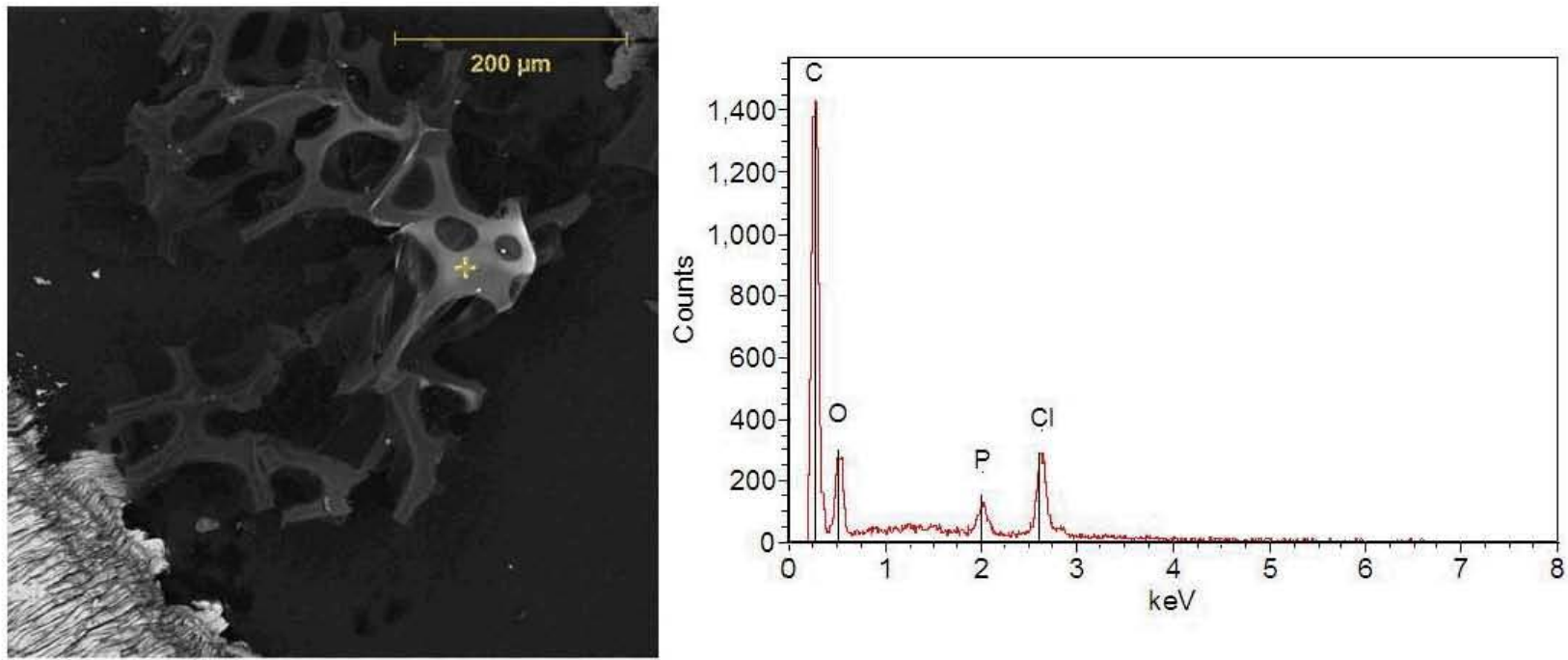


\section{LAB-RPT-12-00007 R0}

\subsubsection{Scanning Electron Microscopy Imaging of the Inner Pipe Surface}

The pipe specimen photographed in Figure 8 was loaded into the SEM and examined. Figure 13 contains backscatter images and demonstrates that the inner surface of pipe SN-285 consists of a coating of tank waste products with islands of corrosion protruding from this layer. The probed EDS location at spot 1 shows an area of iron oxide surrounded by a residue layer rich in chromium, magnesium, aluminum, calcium, and oxygen (EDS spot 2).

\section{Figure 13. Scanning Electron Microscopy Image and Energy Dispersive Spectrometry} Spectra of the Inner Surface of SN-285.
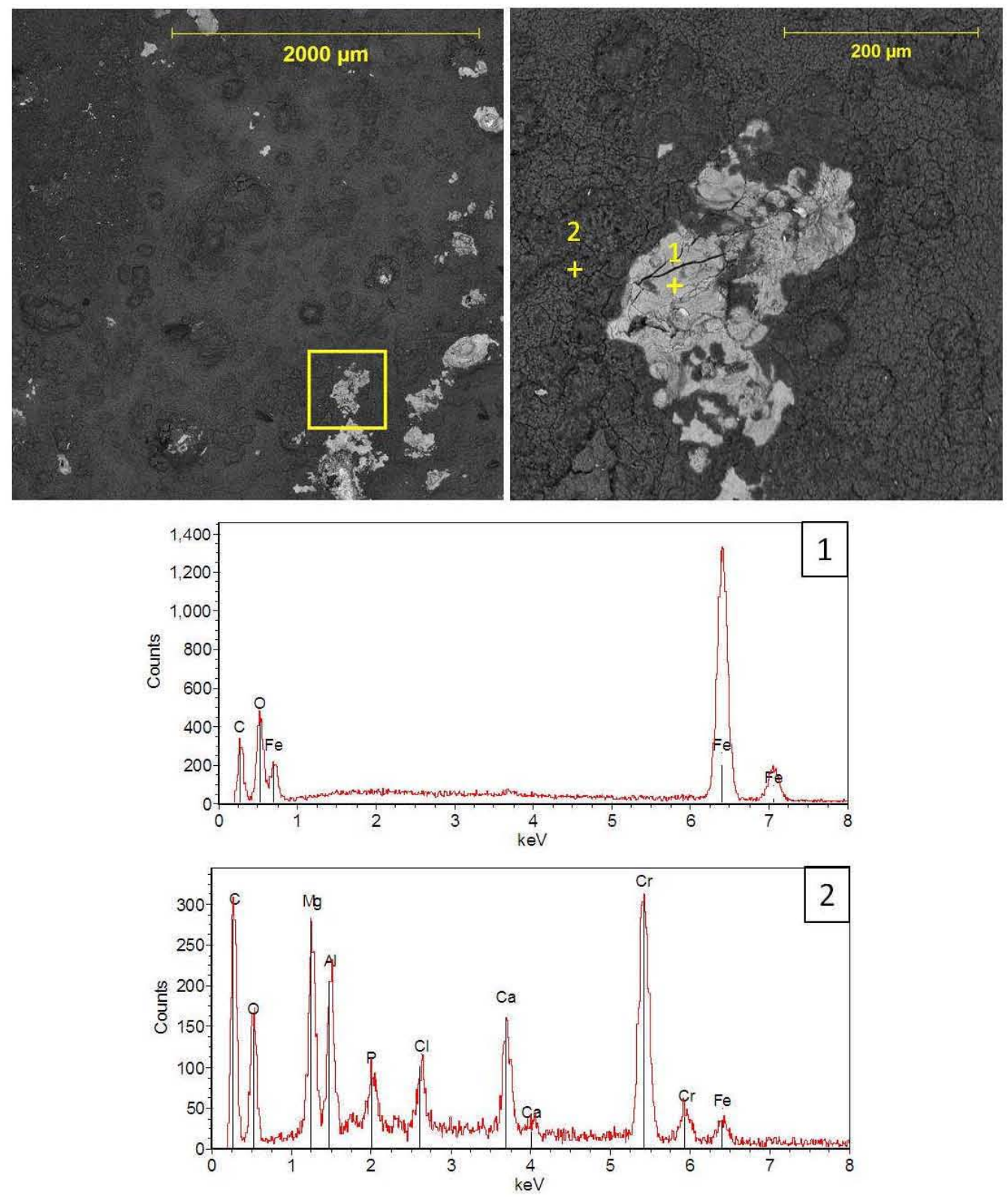


\section{LAB-RPT-12-00007 R0}

Another location on the inner pipe surface was imaged in SEI mode. The secondary electron detector provides good contrast of surface features and depth compared to BEI mode, which uses a backscatter electron detector that gives a flatter picture but contrasts atomic number (element mass). An SEI image in Figure 14A shows the mottled surface of the tank waste residue layer. In the lower right part of the image, a crater feature of pipe corrosion is present. Throughout the surface, small $(<10 \mu \mathrm{m})$ particles of silver were also detected. Some of these particles can be seen in Figure 14B (magnified image of the area in the yellow box in 14A) which was acquired in BEI mode making the silver contrast well with the surrounding residue layer. These silver deposits might be a result of a reduction process created by the cathode protection of the pipeline, RPP-25299, Volume 4: IQRPE DST System Integrity Assessment-Cathodic Protection for DST Transfer Lines.

\section{Figure 14. Secondary Electron Imaging and Backscatter Electron Imaging of the Inner Surface of SN-285 Pipe Section.}
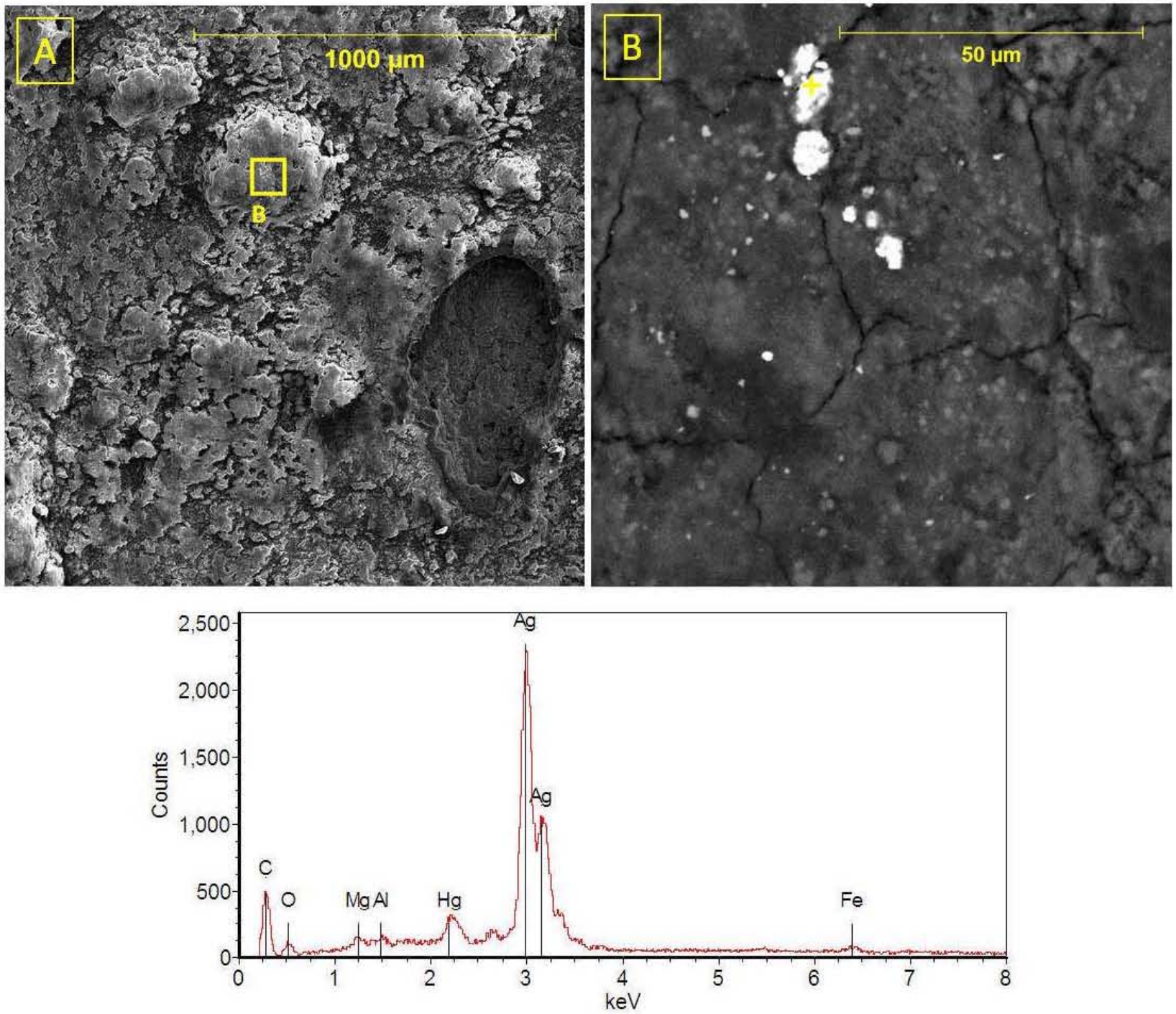


\section{LAB-RPT-12-00007 R0}

\subsubsection{Imaging of Pipe Cross-Section}

In order to obtain information on the tank waste residue layer thickness, corrosion layer thickness, and size of corrosion pitting, a piece of the SN-285 coupon was embedded in epoxy and cross-sectioned. The cross-sectioned specimen was then polished down to a 600 -grit surface. Figure 15 shows photomicrographs of the cross-section with $15 \mathrm{~B}$ as a magnified view of the area inside the yellow box in 15A. The top of the cross-section in the photos is the inner surface of the pipe. The scale bars are in $1 \mathrm{~mm}$ increments. It is possible to see a thin, variable thickness, dark-colored layer on the surface and the presence of small pits. Both of these features are better seen when viewed using the SEM.

Figure 15. Microphotographs of Cross-Sectioned Specimen from SN-285.

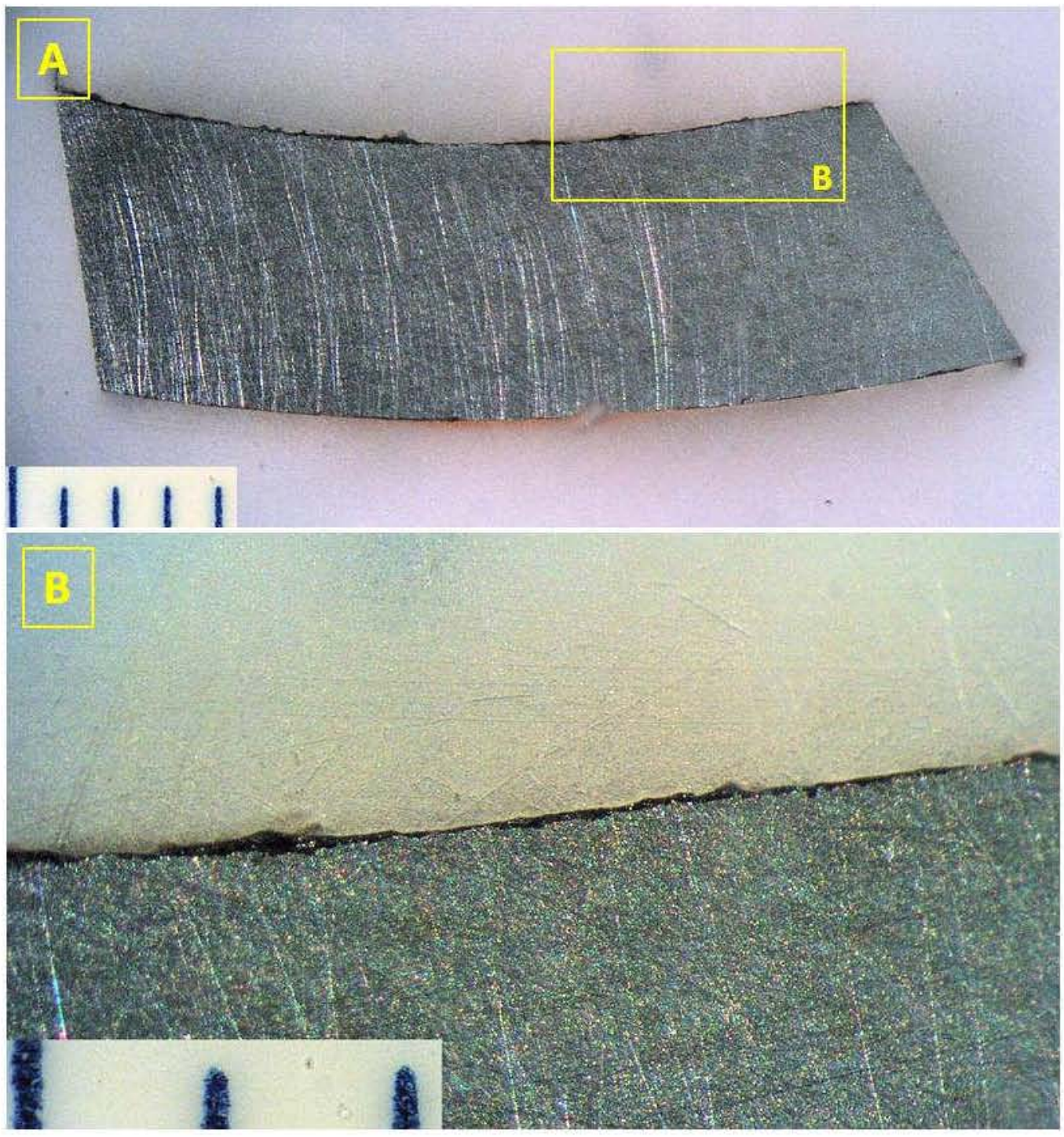




\section{LAB-RPT-12-00007 R0}

Figure 16A shows the same location as in Fig. 15B but imaged with the SEM in BEI mode. The metal appears as the brightest area while the epoxy shows up as the dark area. The intensity of the corrosion layer is between these two levels. Figure $16 \mathrm{~B}$ is a magnified image of the area marked in 16A, and it displays measurements of both the corrosion layer and a pit in the surface. The two EDS spectra indicate that the corrosion layer has the tank waste residue layer on top.

\section{Figure 16. Scanning Electron Microscopy Image and Energy Dispersive Spectrometry Spectra of the Cross-Sectioned Specimen of SN-285.}

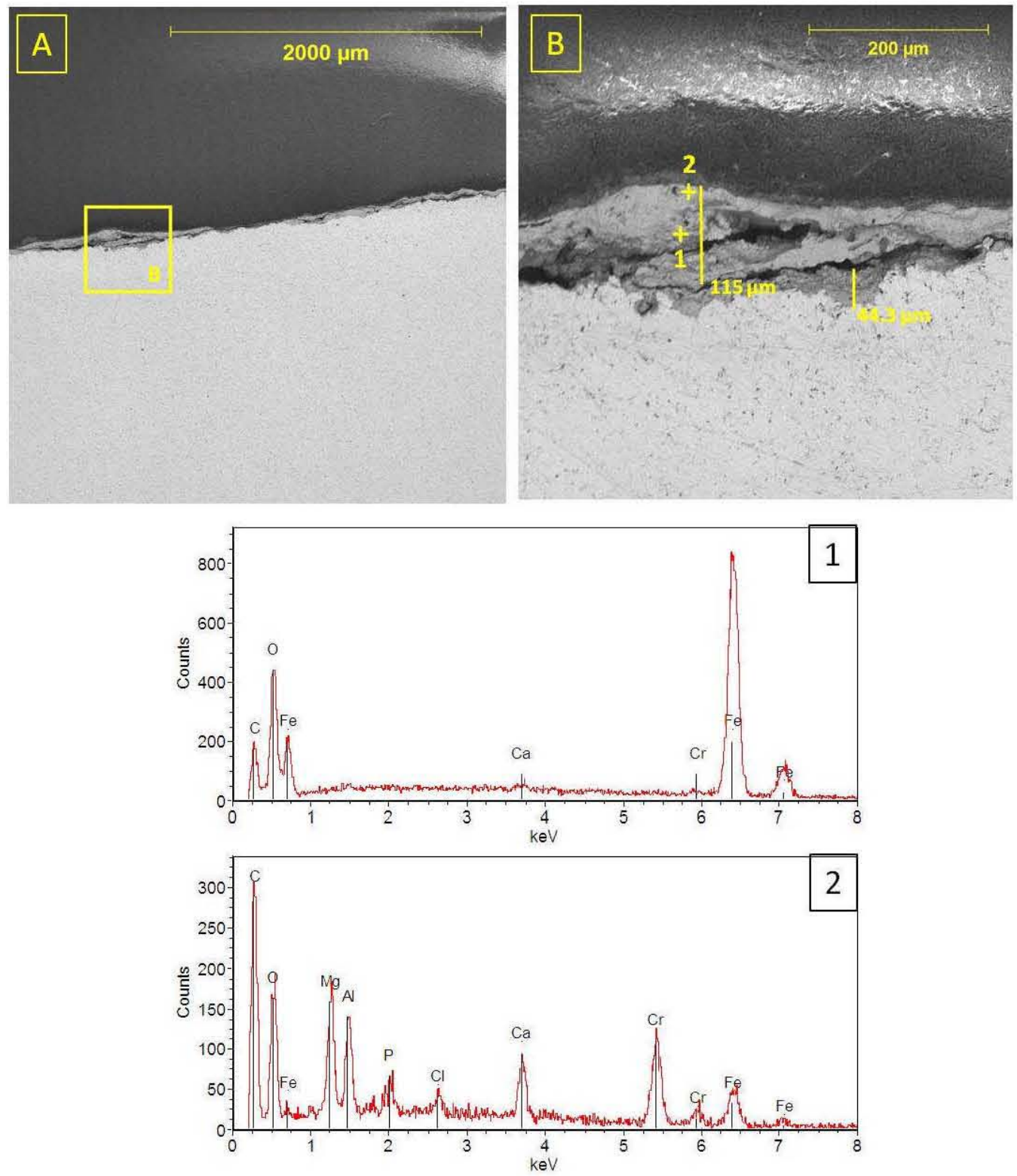

Individual thicknesses of the tank waste and corrosion layer were better defined in another location on the cross-section. Figure 17 shows that the corrosion layer was about 5-times thicker than the residue layer in this area. A depression, or pit, is also present below the corrosion layer with a depth of $\sim 23 \mu \mathrm{m}(1 \mathrm{mil})$. 


\section{LAB-RPT-12-00007 R0}

Figure 17. Scanning Electron Microscopy Image of the Different Layers on the CrossSection of $\mathrm{SN}-285$.

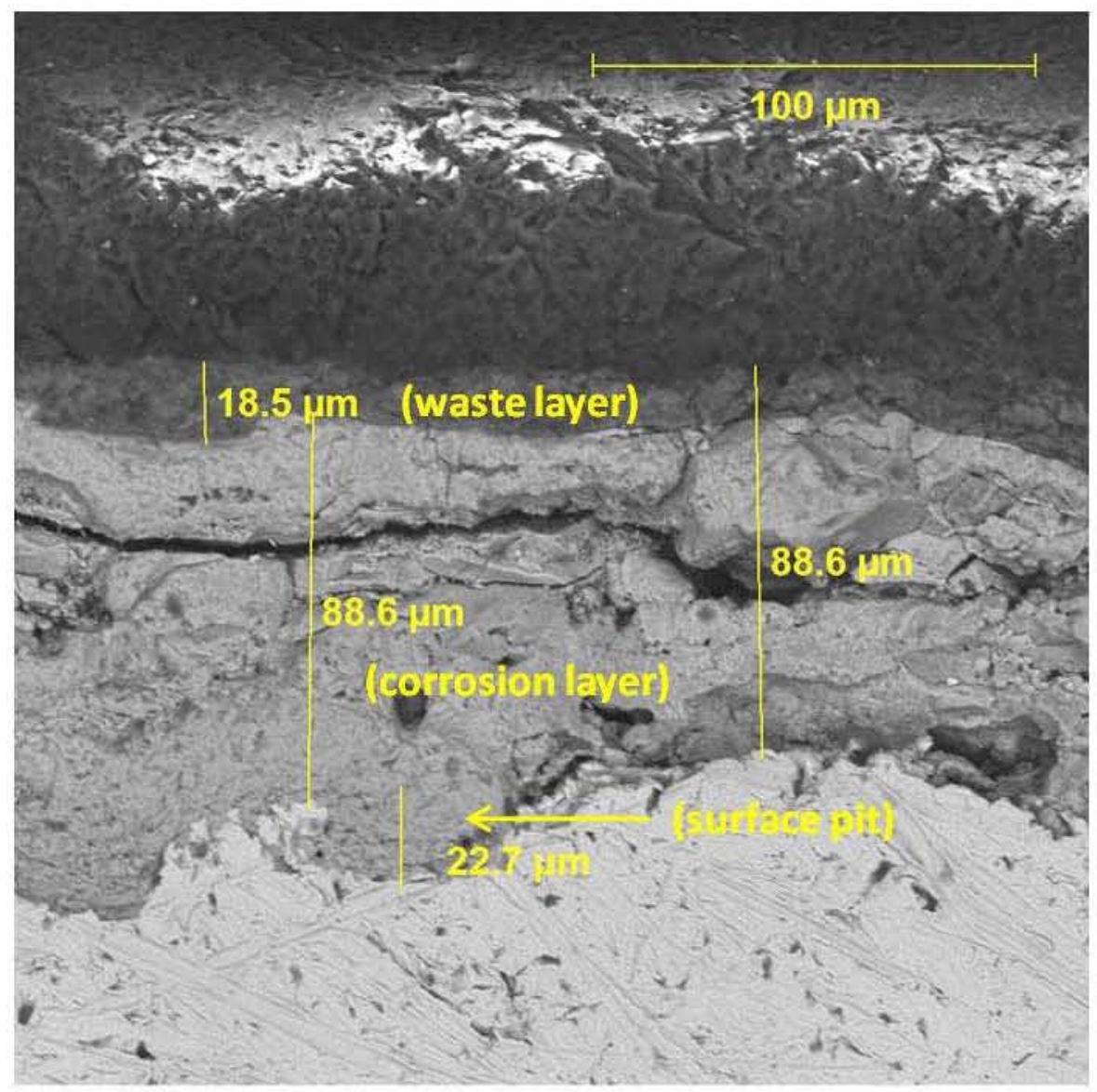

\section{SN-286 EROSION AND CORROSION RESULTS}

\subsection{ULTRASONIC TESTING THICKNESS MEASUREMENT}

A copy of all the results from the UT thickness measurements can be found in Appendix B. The results in inches for SN-286 are transcribed below in Table 2. 
Table 2. Ultrasonic Testing Thickness Measurement Results for SN-286 Pipe Section.

\begin{tabular}{|c|c|c|c|c|c|c|}
\hline $\begin{array}{c}\text { Alpha Numeric } \\
\text { Grid Labels }\end{array}$ & 1 & 2 & 3 & 4 & 5 & 6 \\
\hline A & $.241^{*}$ & .237 & .238 & .244 & .234 & .233 \\
\hline B & .230 & .230 & .228 & .230 & .226 & .228 \\
\hline C & .240 & .234 & .238 & .234 & .237 & .232 \\
\hline D & .237 & .236 & .238 & .235 & .236 & .235 \\
\hline$E$ & .231 & .233 & .231 & .229 & .228 & .225 \\
\hline$F$ & .244 & .245 & .245 & .243 & .243 & .243 \\
\hline G & .240 & .240 & .242 & .240 & .237 & .239 \\
\hline $\mathrm{H}$ & .228 & .230 & .225 & .231 & .228 & .236 \\
\hline I & .241 & .240 & 236 & .237 & .234 & .234 \\
\hline $\mathrm{J}$ & .246 & .241 & .234 & .234 & .232 & .240 \\
\hline K & .241 & .241 & .232 & .238 & .240 & .239 \\
\hline
\end{tabular}

* - All measurements are in inches.

---- - Dotted-line box indicates the approximate area where the coupon was cut.

Overall, there was no obvious low spot in this pipe section. The measurements show a relatively narrow spread in thickness, and these deviations could be from the non-flat outer surface and the variation in the pipe manufacturing. Based upon these results, a $2 \times 2$ in. coupon was cut around the H-3 location which was one of the thinner areas. The thickness of the coupon was measured with a digital caliper at 233 mils. This value corresponds with the thickness measurements using the UT, and it is close to schedule 40 pipe thickness, 216 mils, indicating minimal, if any, corrosion or erosion in this section.

When the coupon was cut from the pipe section, most of the foam detached from the pipe surface as one piece in the hot cell; however, a thin layer of foam still remained on a large portion of the coupon. In order to obtain clear optical and SEM images of the inner surface of the pipe, the rest of the foam was removed by an acetone and water wash using a soft bristled plastic brush.

Before this cleaning process, an area without foam was scraped, and these scrapings were kept for SEM and EDS analysis. Photographs of the coupon both before (A) and after (B) the cleaning are shown in Figure 18. The area in the upper right corner of Figure 18B was where the scrapings were obtained. 
Figure 18. Photographs of the SN-286 Coupon Before and After Cleaning.
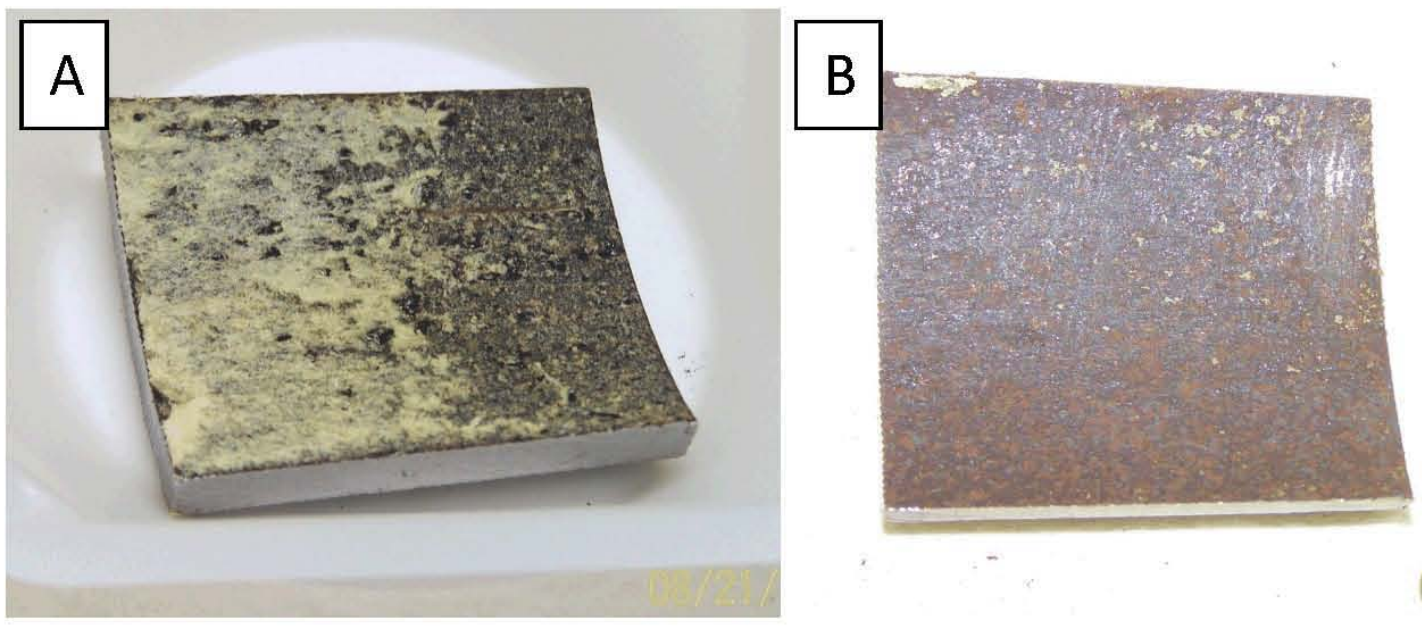

$08 / 23$

\subsection{PHOTOMICROGRAPHY OF THE INSIDE SURFACE}

A smaller piece was cut from the upper right hand part of the coupon in Figure $18 \mathrm{~B}$ to better fit in the SEM. Before being loaded in the SEM, photomicrographs were obtained using a Nikon ${ }^{\circledR}$ reflected light stereo microscope. Figure 19 shows the resulting photomicrographs at two different magnifications with $1 \mathrm{~mm}$ scale bars. The right image is a magnified area of the section in 19A indicated by the yellow box. Overall, the surface appears rough with a layer (or layers) of corrosion and tank waste residue.

Figure 19. Photomicrographs of a Subsection of the SN-286 Coupon.

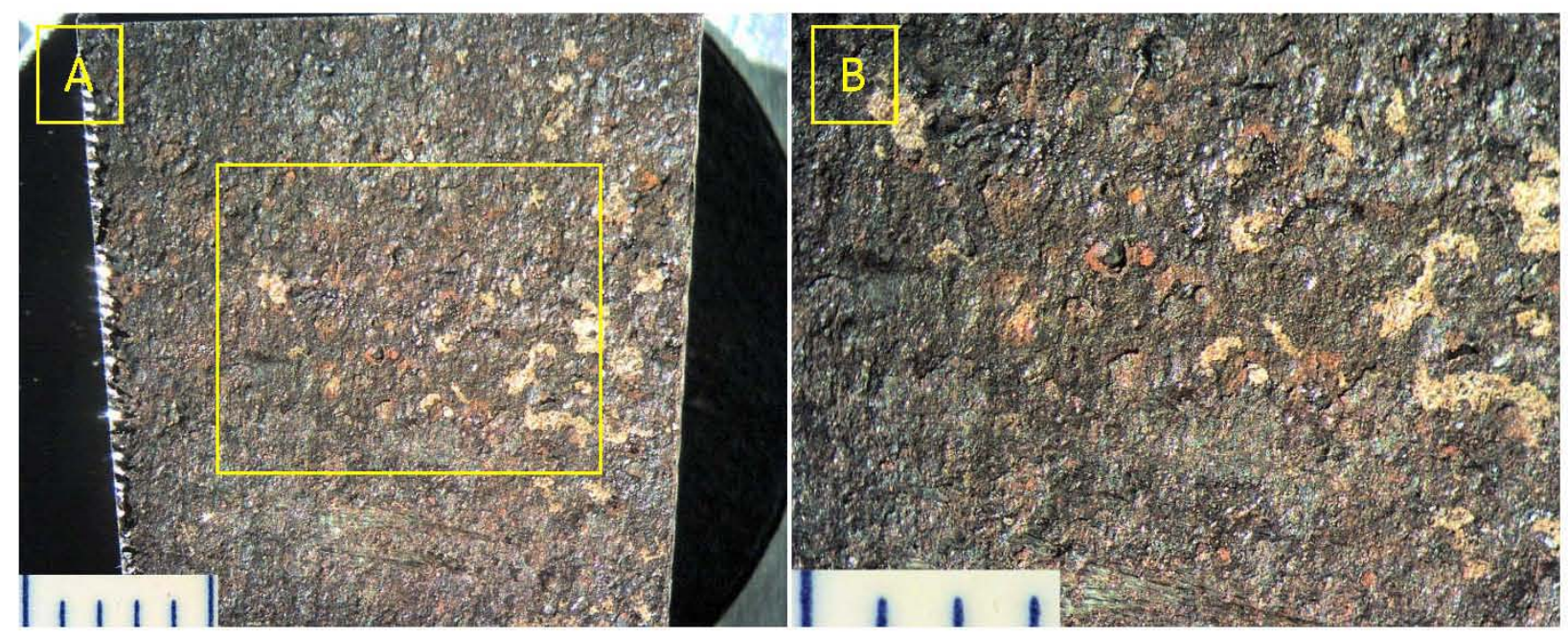




\subsection{SCANNING ELECTRON MICROSCOPY IMAGING}

The SEM analysis was conducted in accordance with ATS-LT-161-100 as detailed in Section 5.3 .

\subsubsection{Scanning Electron Microscopy Imaging of Pipe Scrapings}

The pipe scrapings, taken as described in Section 6.1, were prepared for SEM analysis by lifting them from a plastic weigh boat using a double-sided conductive, carbon adhesive sticker attached to a 1-in. stub. The specimen on the stub was then carbon coated using carbon vapor deposition.

Figure 20 shows a general area on the specimen stub and reveals that the scrapings came off the pipe as isolated and aggregated small particles. Three different areas were chosen for further analysis indicated by the three yellow boxes which refer to following figures where the areas are shown under a higher magnification and with the subsequent EDS analysis of the elemental composition of the particles.

Figure 20. Scanning Electron Microscopy Image of a General Area on the Pipe Scraping Specimen Stub.

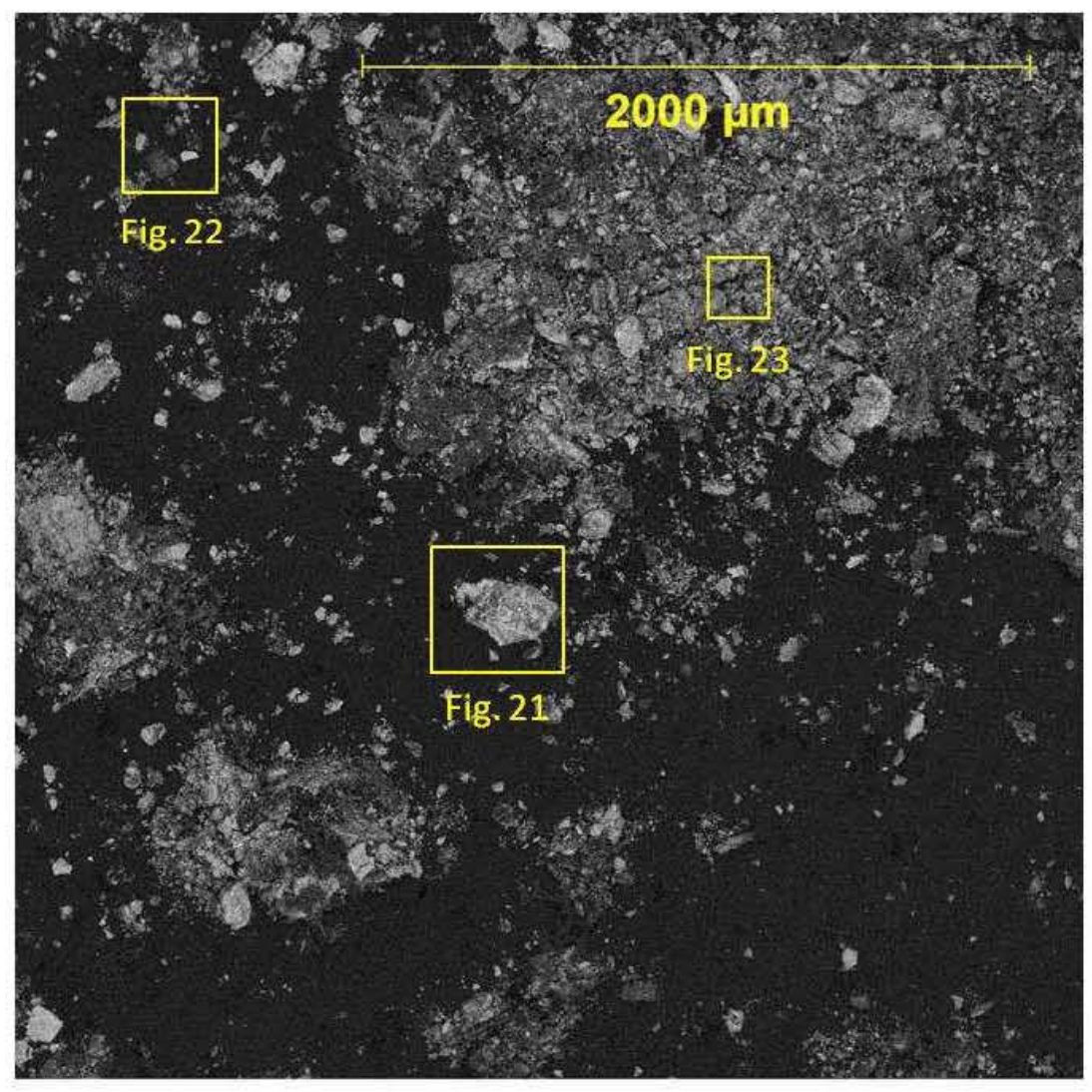




\section{LAB-RPT-12-00007 R0}

Figure 21 shows a larger particle identified by EDS as iron oxide with some tank waste residue on the surface.

Figure 21. Scanning Electron Microscopy Image and Energy Dispersive Spectrometry Spectrum of a Corrosion Particle Scraped from the Inner Surface of SN-286.
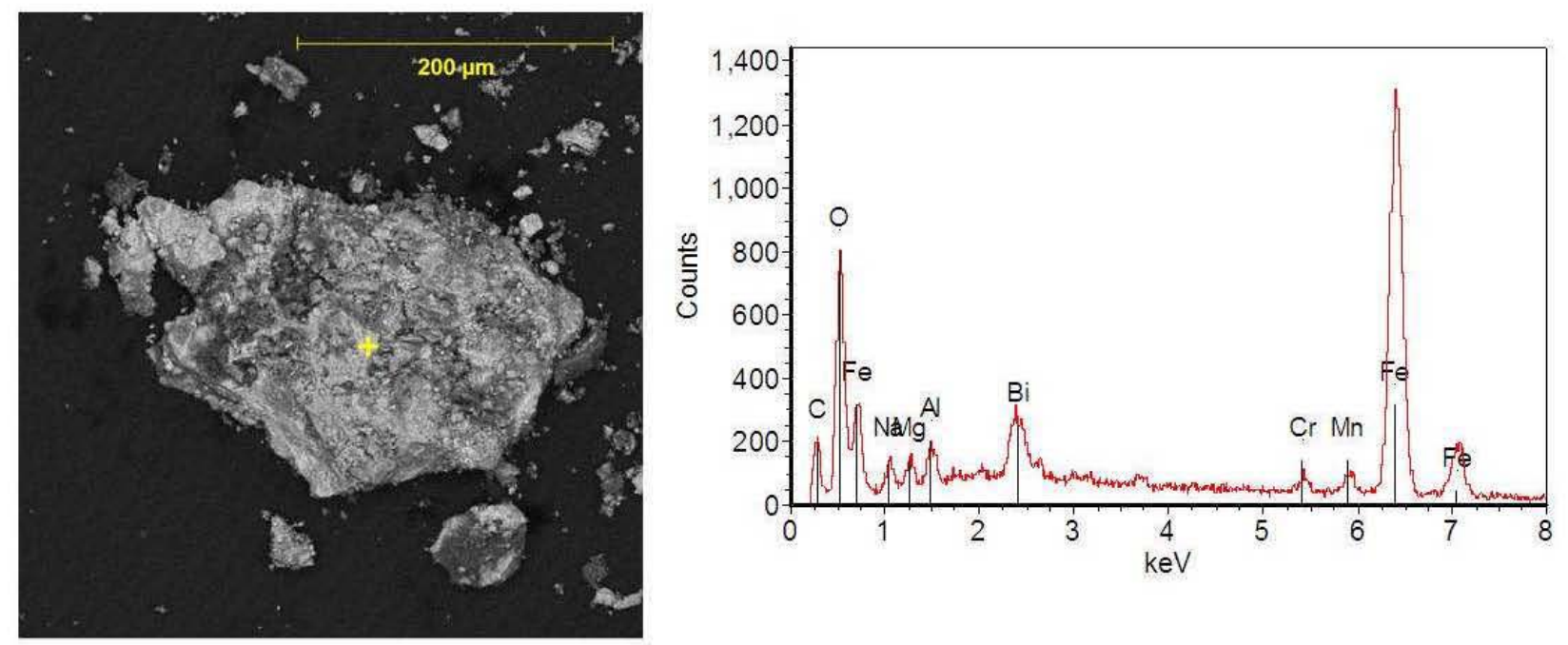

At least two different phases of tank waste were seen in the pipe scrapings. One phase was assigned sodium aluminate and is seen at the EDS analysis spot 1 in Figure 22. An amorphous phase is also present which is rich in iron, aluminum, calcium, sodium, chromium, and phosphorus, and is located at spot 2 . 
Figure 22. Scanning Electron Microscopy Image and Energy Dispersive Spectrom etry Spectrum of Tank Waste Particles Scraped from SN-286.
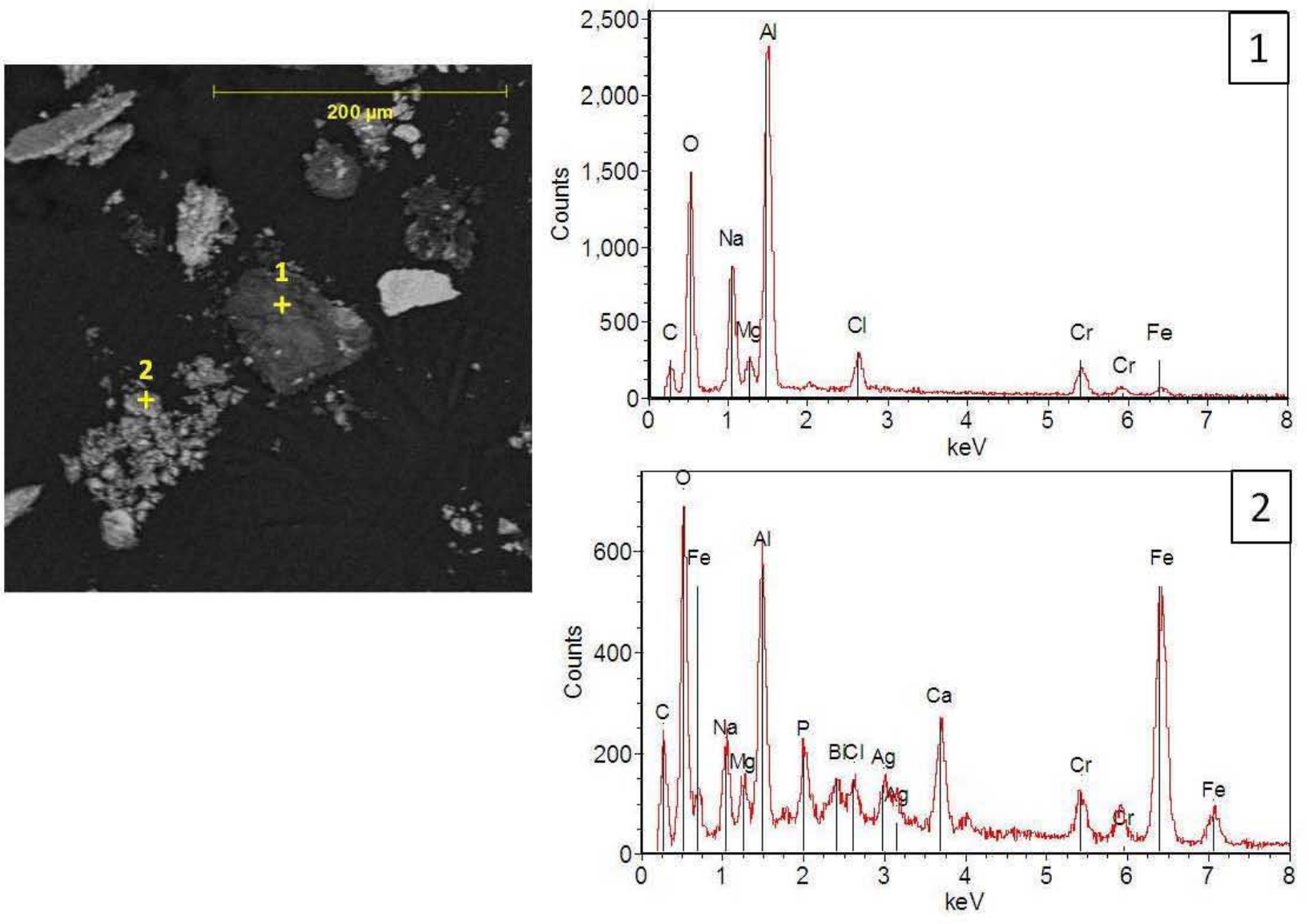

This amorphous phase was the major component in the scrapings from the $\mathrm{SN}-286$ primary pipe section. The chemical variability can be seen in Figure 23 where the levels of the major elements are dissimilar from the EDS analysis in Fig. 22. In addition, the lower level elements are confirmed to be associated with this phase which includes magnesium, silver, bismuth, and chlorine. 


\section{Figure 23. Scanning Electron Microscopy Image and Energy Dispersive Spectrometry} Spectrum of the Majority of the Particulate in the Pipe Scrapings of SN-286.
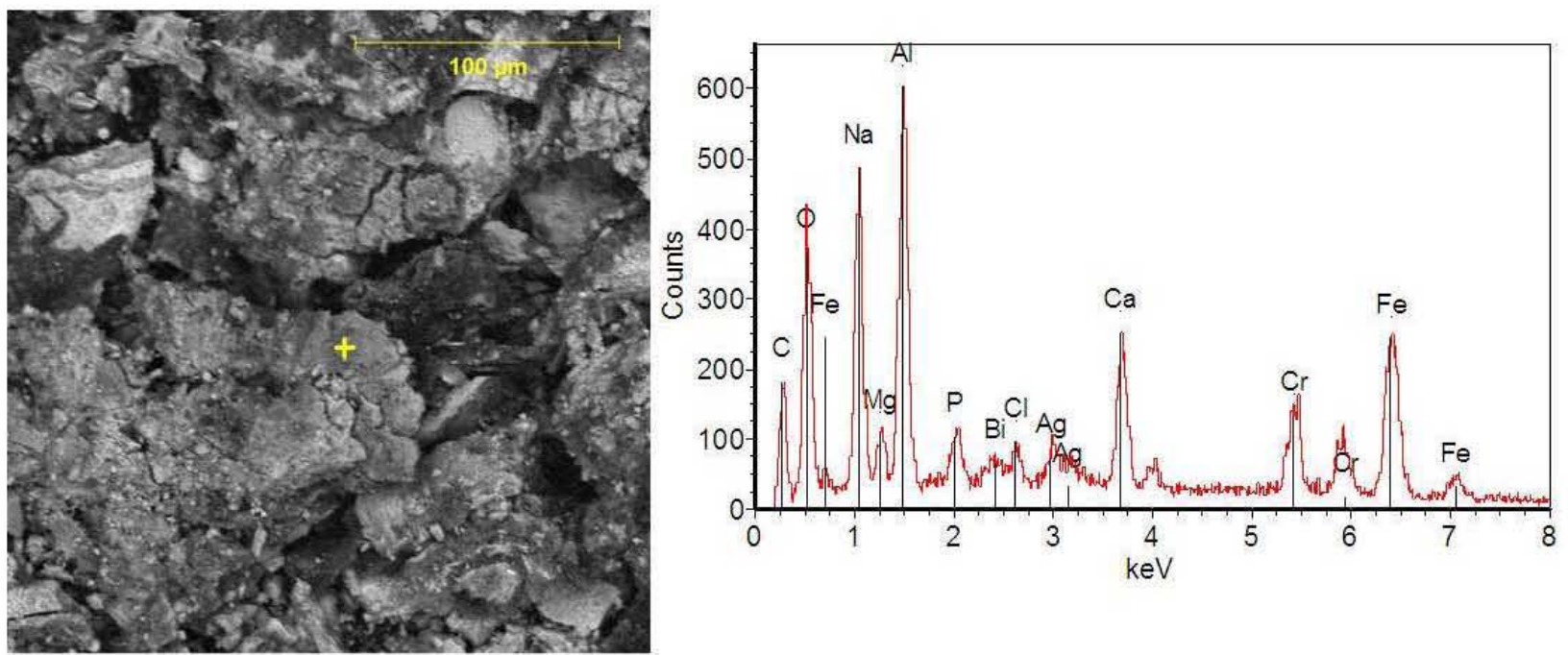

\subsubsection{Scanning Electron Microscopy Imaging of the Inner Pipe Surface}

The pipe specimen photographed in Figure 19 was loaded into the SEM and examined. The SEI in Figure 24A shows the roughness of the surface, and the BEI in Fig. 24B shows that most of the area is covered by the brighter, iron oxide/hydroxide (corrosion) layer with smaller, darker areas of tank waste residue. The magnified area in Figure 24C details better the pockets of tank waste residue on top of the continuous corrosion. The probed EDS spot 1, marked with a yellow cross, detected corrosion with small amounts of tank waste elements, and the EDS spot 2 indicated aluminum oxide, possibly gibbsite, was the tank waste phase on top of the corrosion. 
Figure 24. Scanning Electron Microscopy Image and Energy Dispersive Spectrometry Spectrum of the Inner Wall of Pipe Section SN-286.
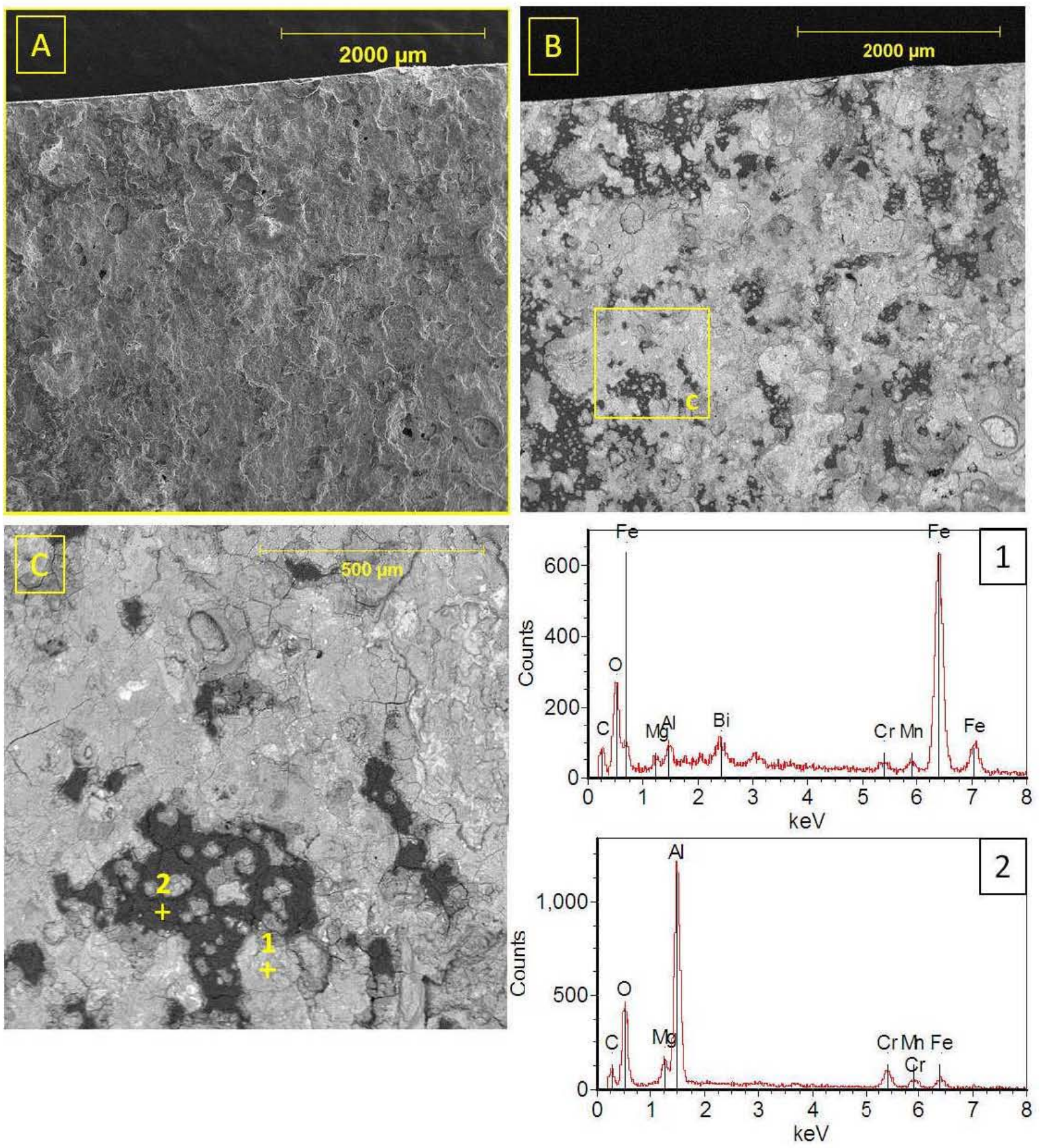


\section{LAB-RPT-12-00007 R0}

In some parts of the aluminum oxide patches, nodules of an amorphous phase were detected (see Figure 25). These contained a large variety of elements as indicated in the labels on the EDS spectrum.

Figure 25. Scanning Electron Microscopy Image and Energy Dispersive Spectrometry Spectrum of an Area on the Inner Surface of Pipe Section SN-286.
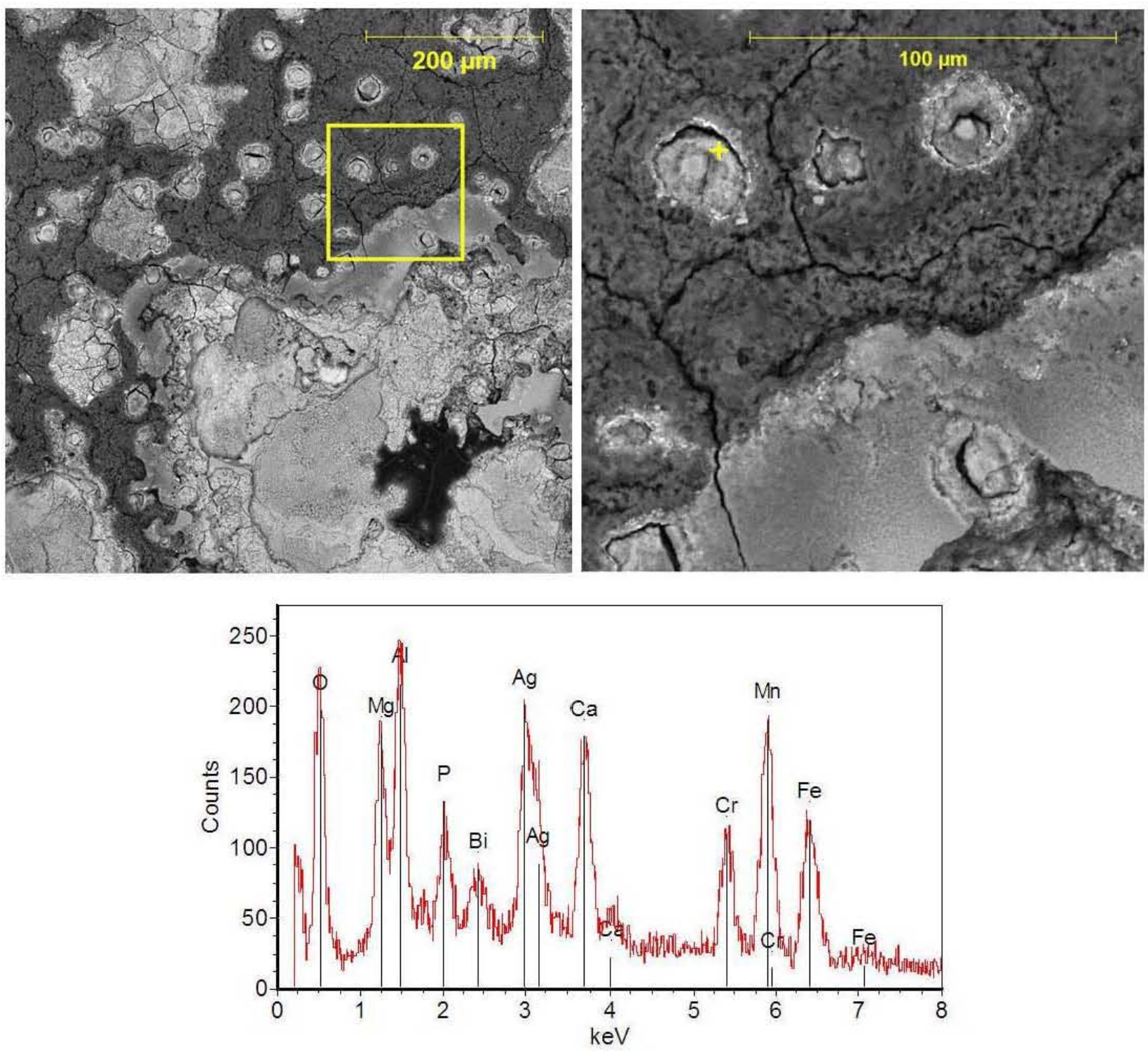

\subsubsection{Imaging of Pipe Cross-Section}

In order to obtain information on the tank waste residue layer thickness, corrosion layer thickness, and size of corrosion pitting, a section of the SN-286 coupon was embedded in epoxy and cross-sectioned. The cross-sectioned specimen was then polished down to a 600 -grit surface. Figure 26 shows photomicrographs of the cross-section; Figure $26 \mathrm{~B}$ is a magnified view 


\section{LAB-RPT-12-00007 R0}

of the area inside the yellow box in Figure 26A. The scale bars are in $1 \mathrm{~mm}$ increments. There are no pits in these pictures large enough to be noticed at this magnification, but the inner pipe surface appears irregular with a thin, dark film on the entire surface.

Figure 26. Photomicrographs of Cross-Sectioned Specimen from SN-286.

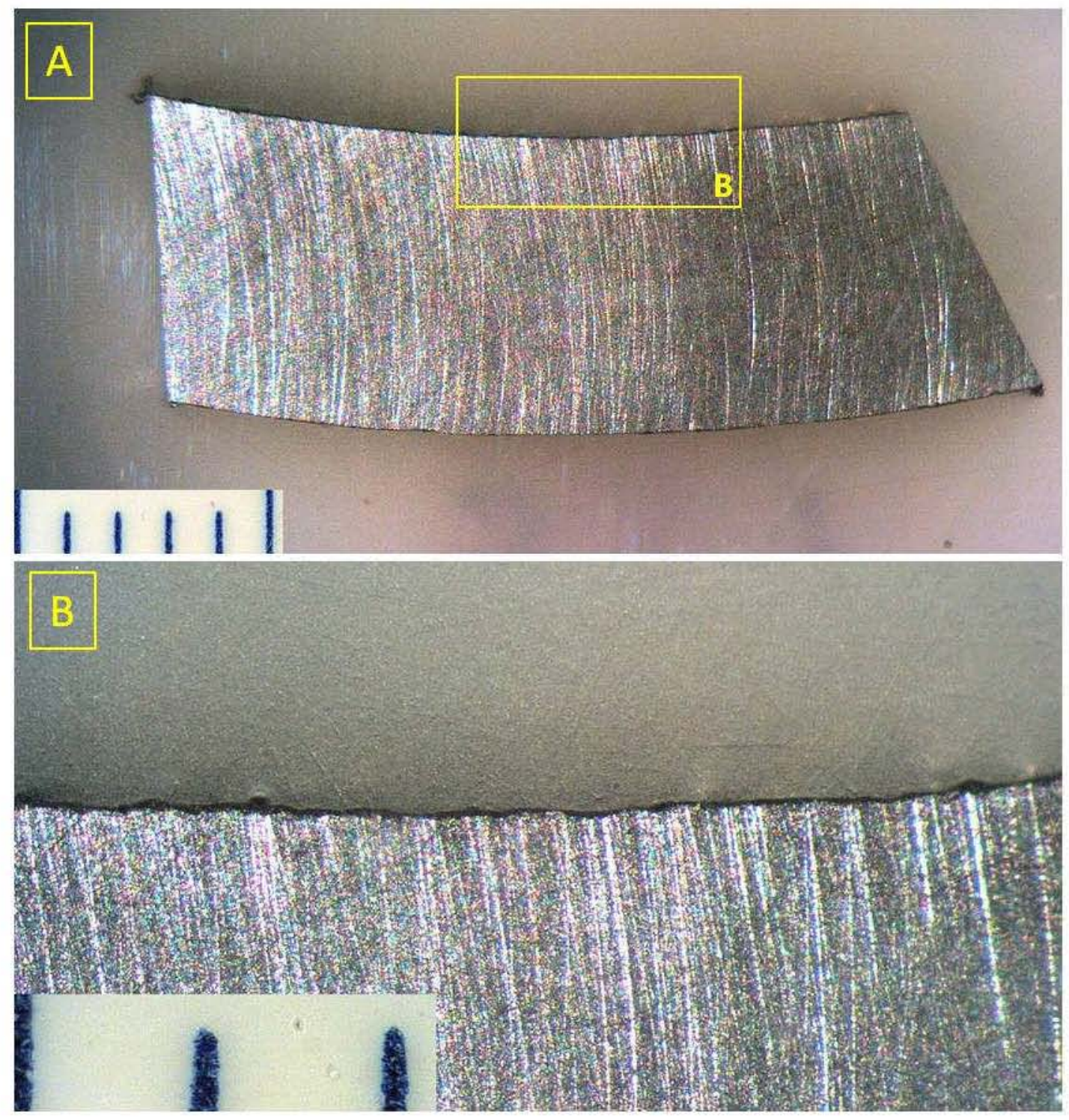

Small pits do show up using the increased magnification of the SEM. Figure 27 shows an area on the cross-sectioned coupon at two different magnifications (the right image is a magnified view of the area in the yellow box of the left image). In general, the pits were measured at less than $50 \mu \mathrm{m}$ ( 2 mils) in depth. The EDS spectrum indicates that the dark layer on the surface of the pipe is corrosion with trace elements of tank waste origin. 
Figure 27. Scanning Electron Microscopy Image and Energy Dispersive Spectrometry Spectra of the Cross-Sectioned Specimen of SN-286.
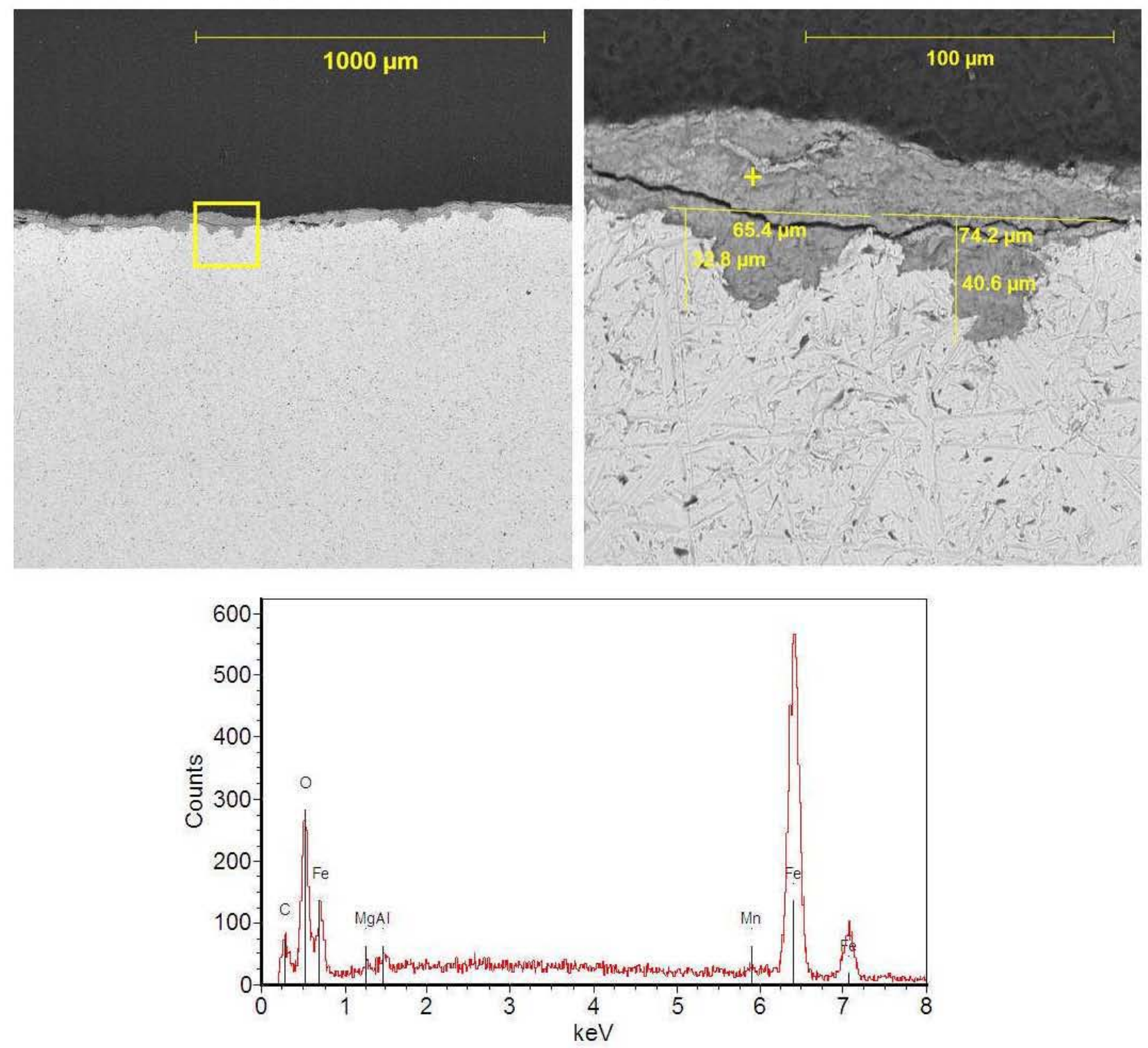

The continuous corrosion layer on the inner surface of the SN-286 pipe section ranged between $40(1.5 \mathrm{mils})$ to $60 \mu \mathrm{m}(2.5 \mathrm{mils})$ in thickness, Figure $28 \mathrm{~A}$. Throughout this layer, individual particles of aluminum oxide tank waste (possible gibbsite) were observed as shown in Figure $28 \mathrm{~B}$. All the aluminum oxide particles detected in this cross-section were below the corrosion layer and adjacent to the metal surface. 


\section{LAB-RPT-12-00007 R0}

Figure 28. Scanning Electron Microscopy Image and Energy Dispersive Spectrometry Spectrum of the Corrosion Layer on SN-286 Inner Pipe.

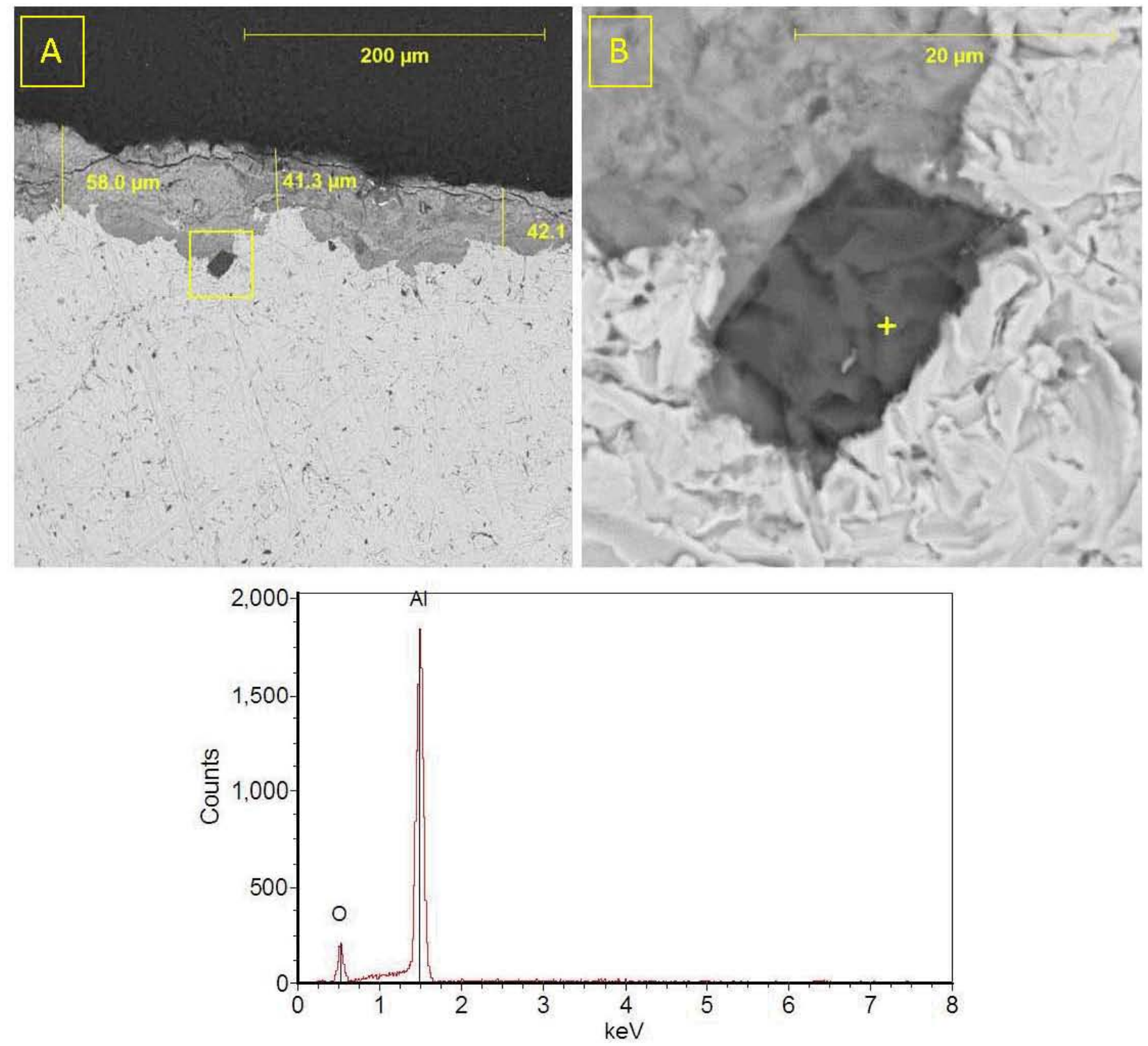

7 SN-278 EROSION AND CORROSION RESULTS

\subsection{ULTRASONIC TESTING THICKNESS MEASUREMENT}

A copy of all the results from the UT thickness measurements can be found in Appendix B. The results (in inches) for $\mathrm{SN}-278$ are transcribed below in Table 3. 
Table 3. Ultrasonic Testing Thickness Measurement Results for SN-278 Pipe Section. Alpha Numeric

\begin{tabular}{|r|cccc|}
\multicolumn{1}{|c}{ Grid Labels } & 1 & 2 & 3 & 4 \\
\hline A & $.225^{*}$ & .230 & .224 & .231 \\
B & .235 & .230 & .231 & .225 \\
C & .228 & .224 & .225 & .220 \\
D & .222 & .235 & .223 & .222 \\
E & .222 & NA** $^{*}$ & .220 & .229 \\
F & .215 & .215 & .219 & .219 \\
G & .224 & .223 & .223 & .225 \\
H & .216 & .219 & .218 & .220 \\
I & .219 & .210 & .215 & .216 \\
J & .227 & .223 & .225 & .222 \\
K & .223 & .220 & .219 & .219
\end{tabular}

* - All measurements are in inches.

** - Location of hole in the pipe; no measurement could be made.

---- - Dotted-line box indicates the approximate area where the coupon was cut.

Similar to the previous two pipe sections, there were no obvious thin spots in this pipe section. Based upon the UT results, a 2 X 2 in. coupon was cut around the I- 2 location on the pipe. The thickness of the coupon was measured with a digital caliper at 227 mils. This corresponds with the thickness measurement using the UT, and it is close to schedule 40 pipe thickness (216 mils) indicating minimal, if any, corrosion or erosion in this section.

When the coupon was cut from the pipe section, most of the foam detached from the pipe surface as one piece; however, several small bits of foam still remained on the coupon. In order to obtain clear optical and SEM images of the inner surface of the pipe, this foam and much of the dark brown material was removed by an acetone and water wash using a soft bristled plastic brush. Before this cleaning process, however, an area without foam was scraped, and these scrapings were kept for SEM and EDS analyses. Photographs of the coupon both before (A) and after (B) the cleaning are shown in Figure 29. The area on the left side of the coupon, Figure 29B, was where the scrapings were obtained. 
Figure 29. Photographs of the SN-278 Coupon Before and After Cleaning.
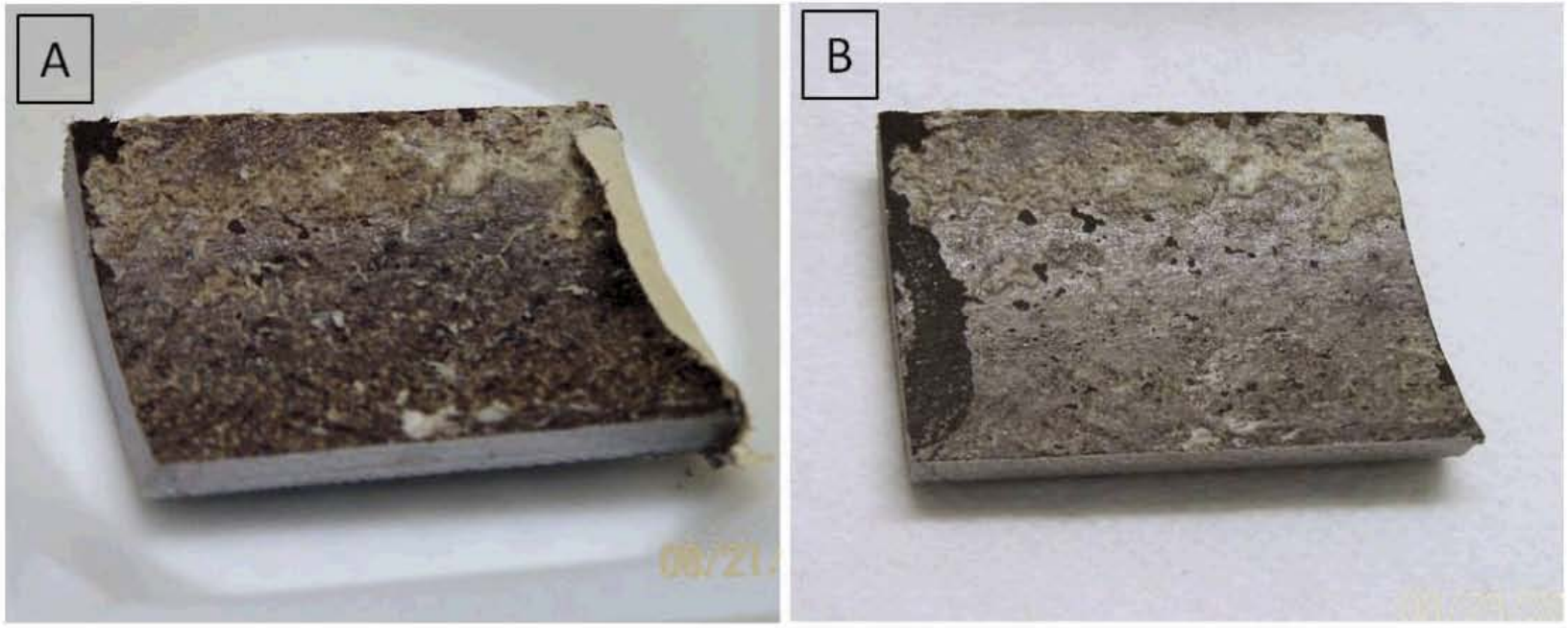

\subsection{MICROPHOTOGRAPHY OF THE INSIDE SURFACE}

A smaller piece of pipe was cut from the lower left-hand part of the coupon in Figure $29 \mathrm{~B}$ to better fit in the SEM. Before being loaded in the SEM, photomicrographs were obtained using a Nikon ${ }^{18}$ reflected light stereo microscope. Figure 30 shows the resulting photomicrographs at two different magnifications with a $1 \mathrm{~mm}$ scale bar in the images. The right image is a magnified area of the section in Figure 30A indicated by the yellow box. Overall, the surface displayed a thin, flaky layer that easily scraped off. This layer appeared detached in some locations in Figure 30B. Under the layer, where the scrapings occurred, the pipe surface looked furrowed with lines running along the pipe length.

Figure 30. Photomicrographs of a Subsection of the SN-278 Coupon.
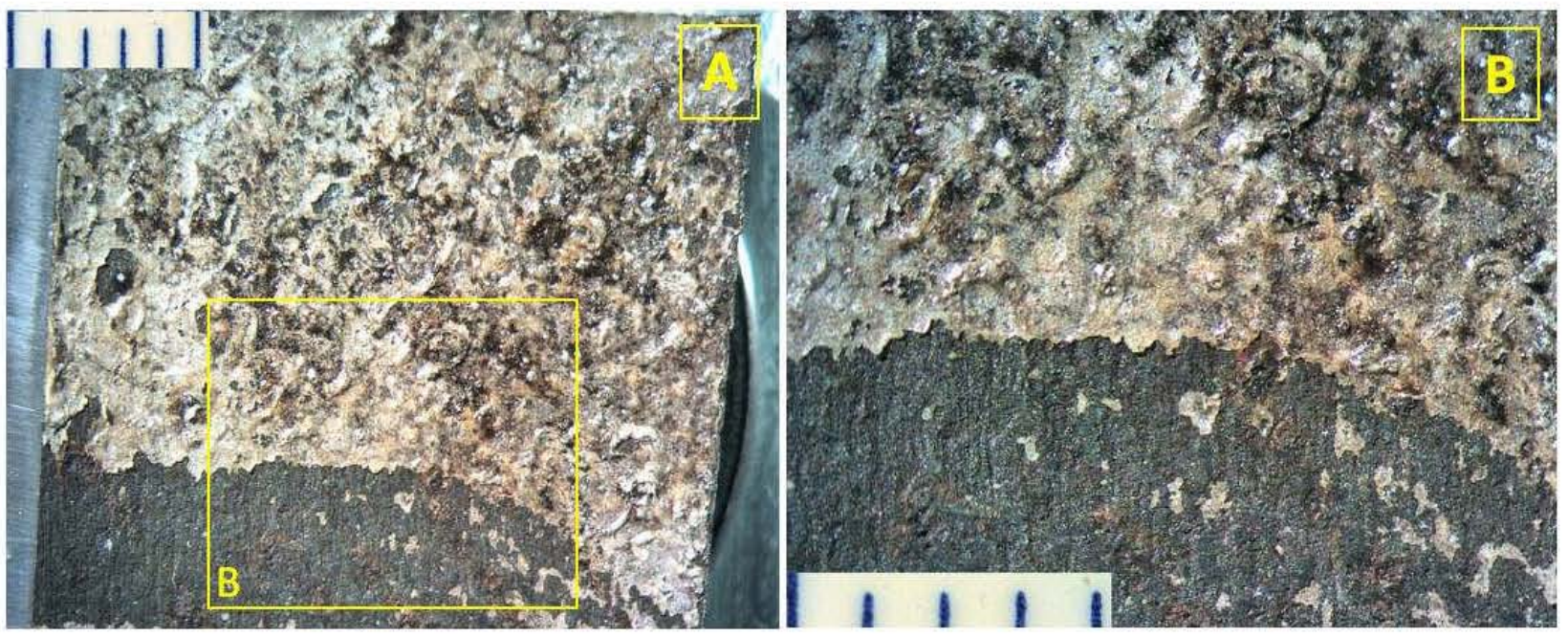


\subsection{SCANNING ELECTRON MICROSCOPY IMAGING}

The SEM analysis was conducted in accordance with ATS-LT-161-100 as detailed in Section 5.3.

\subsubsection{Scanning Electron Microscopy Imaging of Pipe Scrapings}

The pipe scrapings, taken as described in Section 7.1, were prepared for SEM analysis by lifting them from a plastic weigh boat using a double-sided conductive, carbon adhesive sticker attached to a 1-in. stub. The specimen on the stub was then carbon coated using carbon vapor deposition.

Figure 31 shows a general area on the specimen stub and shows one of the large, thin flakes scraped from the inside surface of the pipe section. The flake appeared to be an aggregate of fine-grained aluminum oxide particulate (possible gibbsite) as indicated by the EDS spectra from spot 1 . The brighter area in the BEI shows the presence of a calcium phosphate residue on this aluminum oxide layer. 


\section{LAB-RPT-12-00007 R0}

Figure 31. Scanning Electron Microscopy Image of a General Area on the SN-278 Pipe Scraping Specimen Stub.
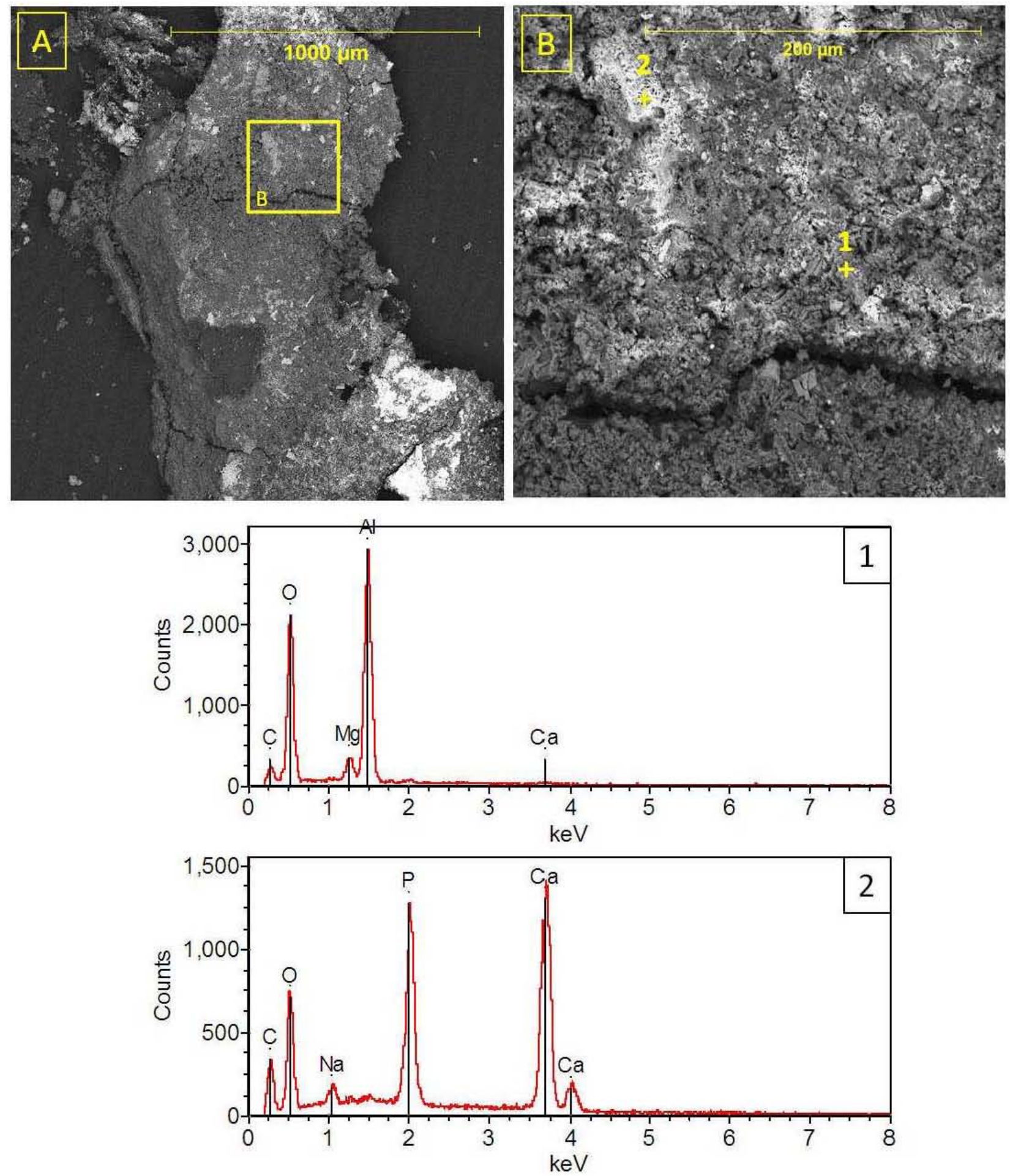

Another flake is shown in Figure 32, which is possibly the underside of the particle, as there is a platy, iron oxide phase which could have been pulled from the pipe wall. 


\section{LAB-RPT-12-00007 R0}

Figure 32. Scanning Electron Microscopy Image and Energy Dispersive Spectrometry Spectrum of a Flake Scraped from the SN-278 Pipe Section.
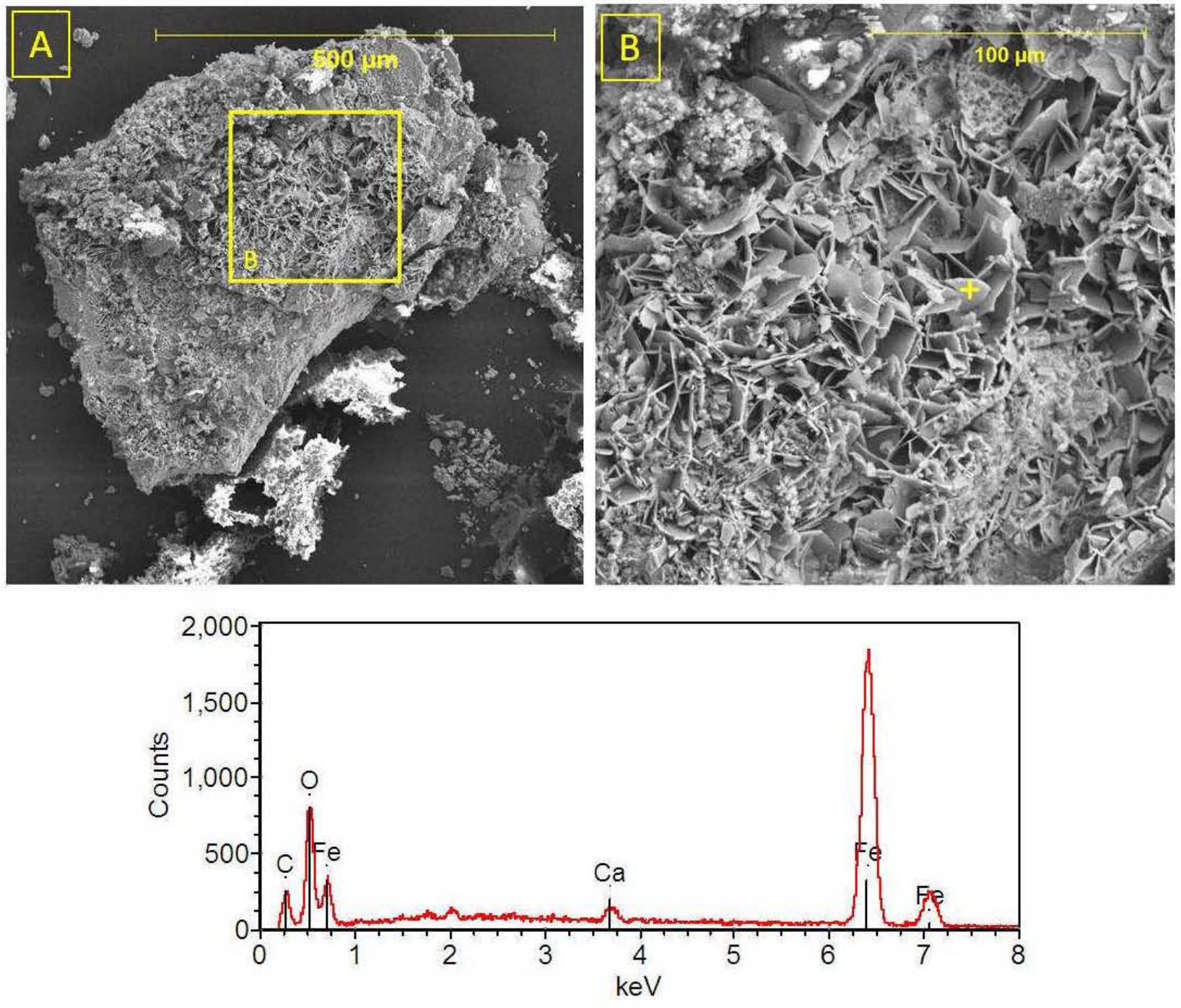

Another type of flaky particle scraped from the pipe surface is shown in Figure 33. This particle contained carbon and chloride, and this could represent the top side of the flakes as its appearance is similar to the images in the following section which show the SEM results of the intact inside surface of the pipe. 


\section{LAB-RPT-12-00007 R0}

Figure 33. Scanning Electron Microscopy Image and Energy Dispersive Spectrom etry Spectrum of Another Flake Scraped From SN-278.
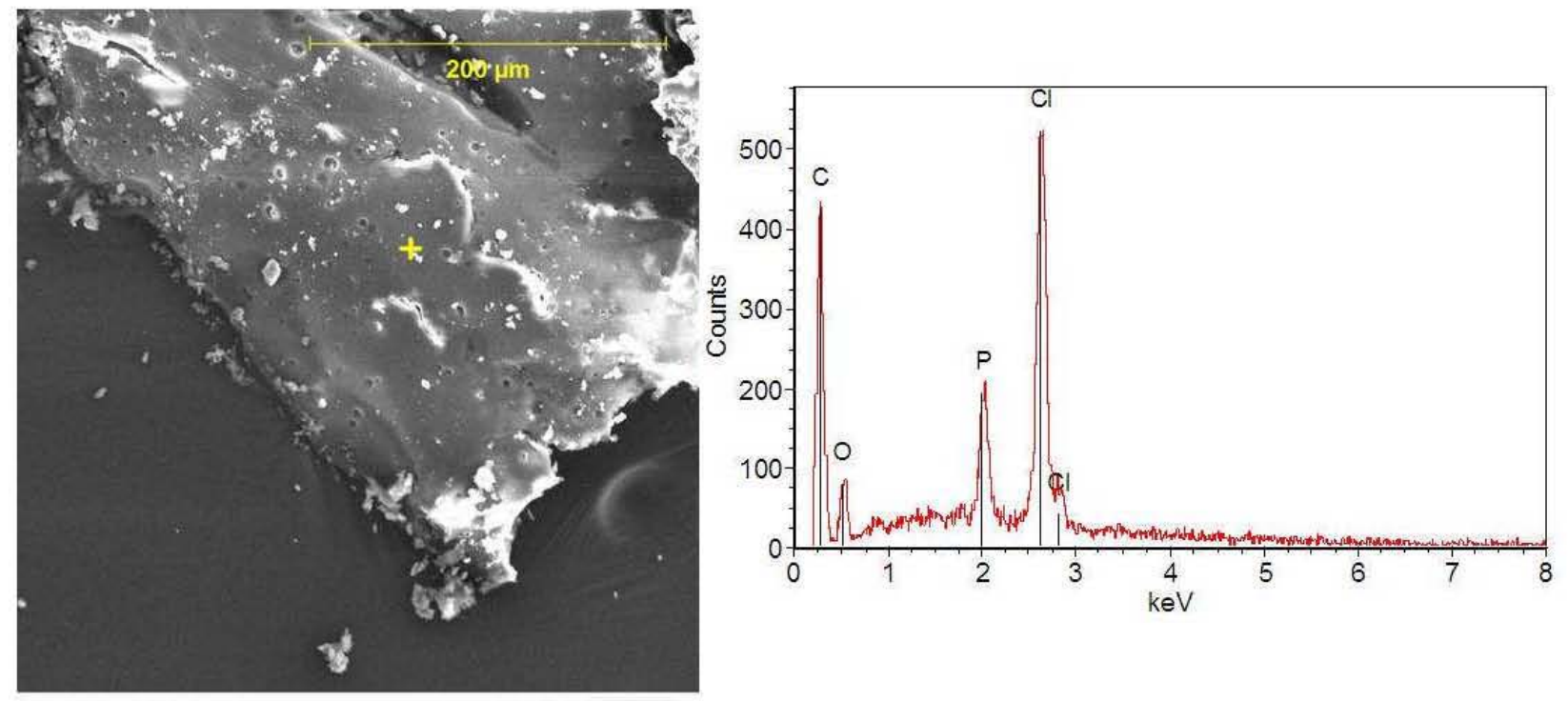

\subsubsection{Scanning Electron Microscopy Imaging of the Inner Pipe Surface}

The primary pipe specimen photographed in Figure 30 was loaded into the SEM and examined. Figure 34 shows the resulting images of a location which borders an area which was scraped. The thin layer, detached in places, is evident in the lower parts of the images. The bare metal surface in the upper part of the images shows grooves which ran the length of the pipe. The image in Figure 34B is a magnified area of the yellow box in Figure 34A in which the grains of the metal can be seen as rounded nodules in the upper part of the figure. It appears that the corrosion in this area occurred at grain boundaries.

The EDS analysis of the flaky layer showed the same phases as were detected in the pipe scrapings. Spot 1 shows the presence of the carbon-, chlorine-, and phosphate-rich phase while EDS spot 2 contains both the aluminum oxide and calcium phosphate phases. 


\section{LAB-RPT-12-00007 R0}

Figure 34. Scanning Electron Microscopy Image and Energy Dispersive Spectrometry Spectra of the Inner Wall of Pipe Section SN-278.
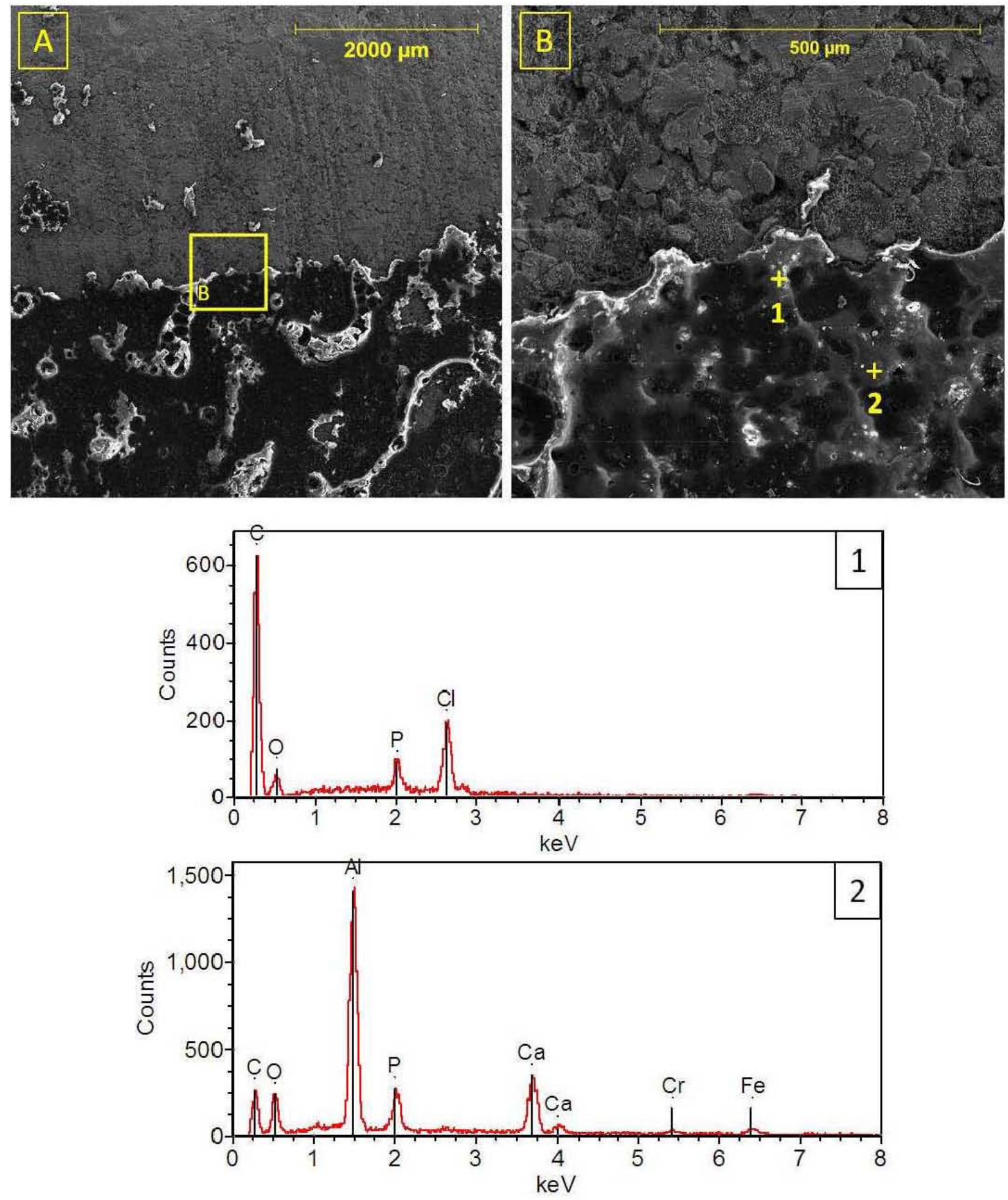
Looking at the bare pipe surface at a higher magnification reveals the presence of two morphologies in the corrosion phase: granular and acicular, Figure 35, on top of the exposed grains of the metal.

Figure 35. Scanning Electron Microscopy Image and Energy Dispersive Spectrometry Spectrum of Corrosion on the Exposed Grains of the Metal.
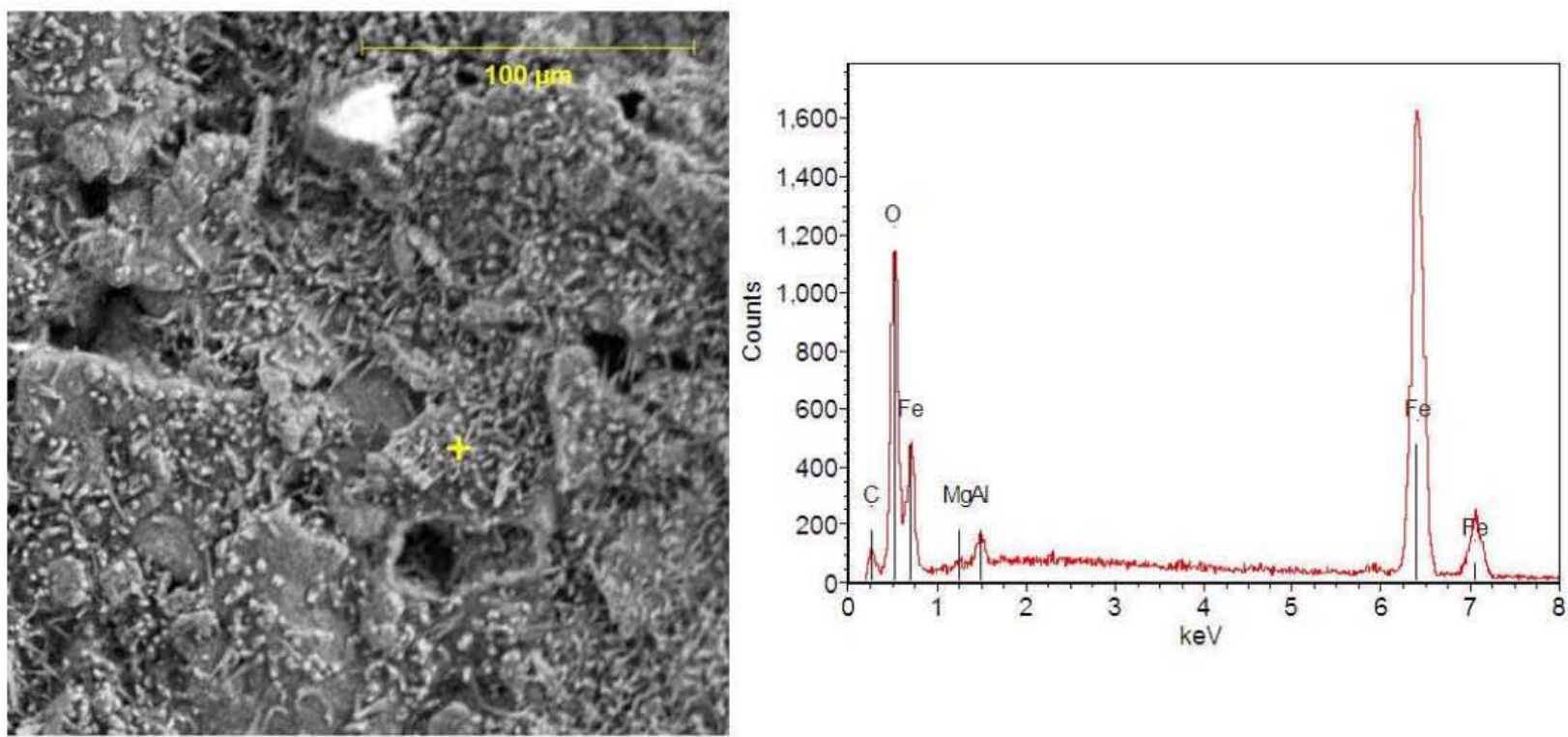

Pits were also observed on the exposed pipe surface. Figure 36 shows two of the pits with one measuring 171 X $75 \mu \mathrm{m}$ ( 7 X 3 mils).

Figure 36. Scanning Electron Microscopy Image and Energy Dispersive Spectrometry Spectrum of Pitting on the Inner Surface of the Pipe.
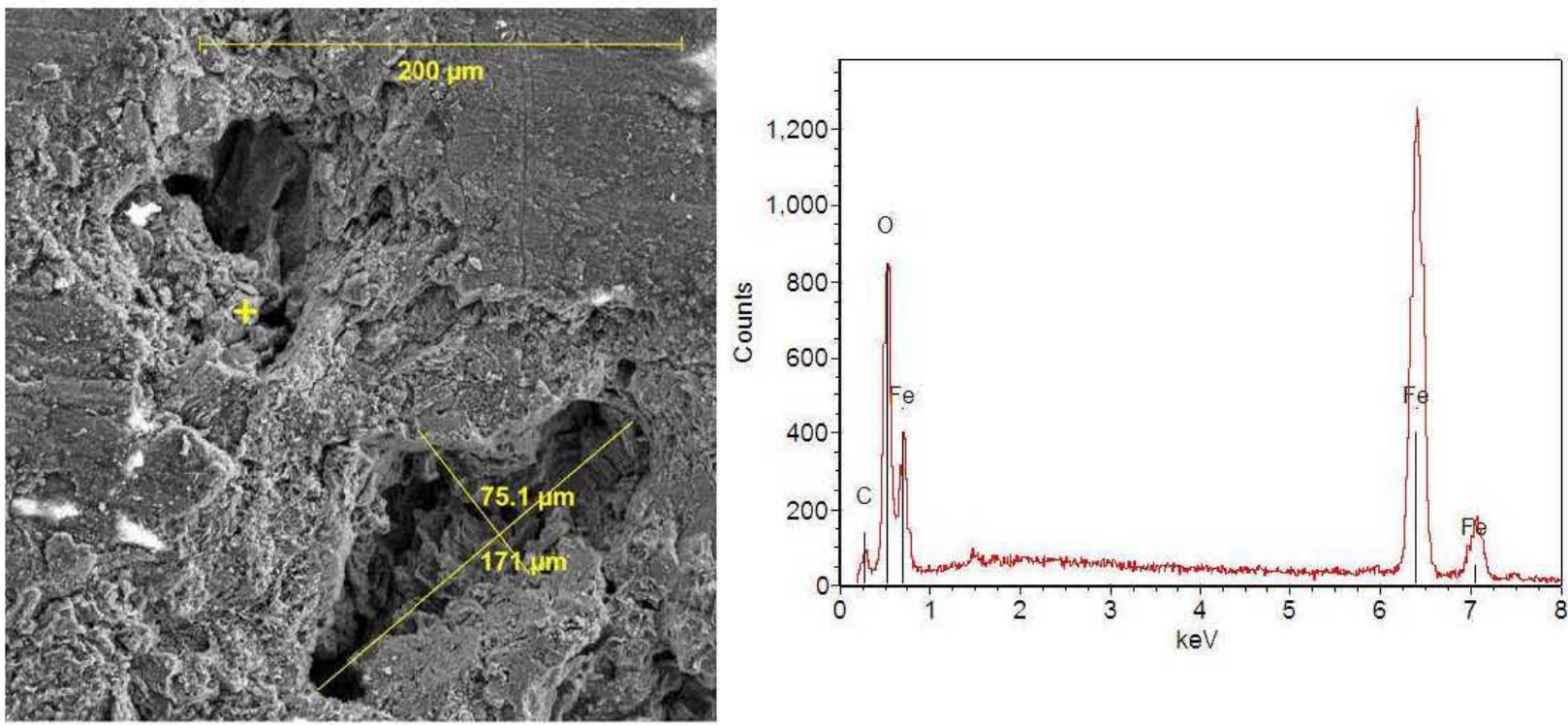


\section{LAB-RPT-12-00007 R0}

\subsubsection{Imaging of Pipe Cross-Section}

In order to obtain information on the flaky residue layer thickness, corrosion layer thickness, and the depth of corrosion pitting, a section of the SN-278 coupon was embedded in epoxy and cross-sectioned. The cross-sectioned specimen was then polished down to a 600 -grit surface. Figure 37 shows photomicrographs of the cross-section with Figure 37B as a magnified view of the area inside the yellow box in Figure 37A. The scale bars are in $1 \mathrm{~mm}$ increments. There were some noticeable pits even at this magnification, and the inner pipe surface appeared irregular with a thin, dark film on the entire surface covered in some areas by a thicker darkbrown layer.

\section{Figure 37. Photomicrographs of Cross-Sectioned Specimen from SN-278.}

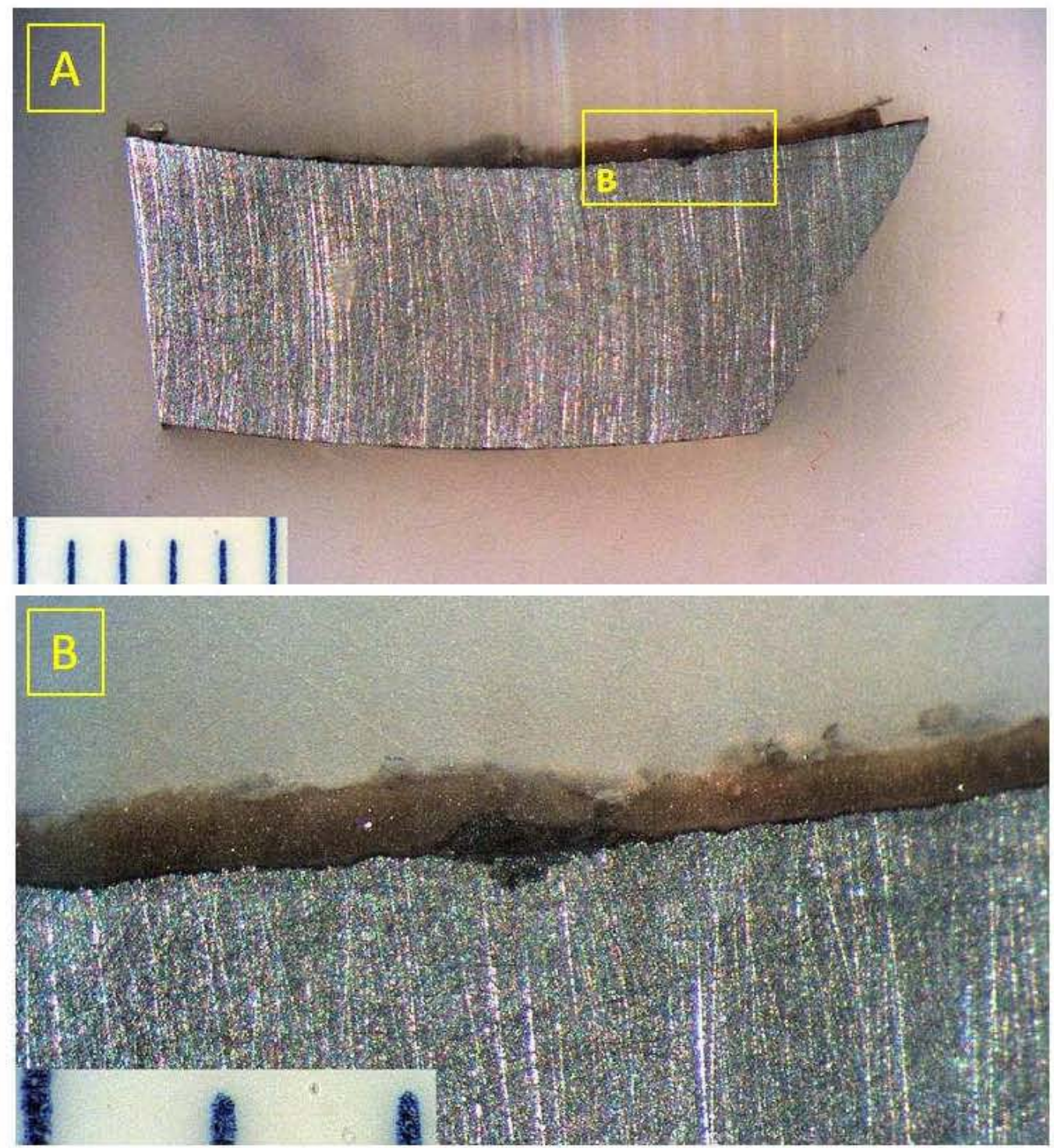

The pit in the center of the photo in Figure 37B is shown as SEM images at different magnifications in Figure 38. Here, the pit, measuring $209 \mu \mathrm{m}$ ( 8 mils) deep, has corrosion in and 
directly above the pit. On both sides of the corrosion, a relatively thick layer, $\sim 350 \mu \mathrm{m}$ (14 mils), of aluminum oxide, possibly gibbsite, is present.

Figure 38. Scanning Electron Microscopy Image and Energy Dispersive Spectrometry Spectra of the Cross-Sectioned Specimen of SN-278.
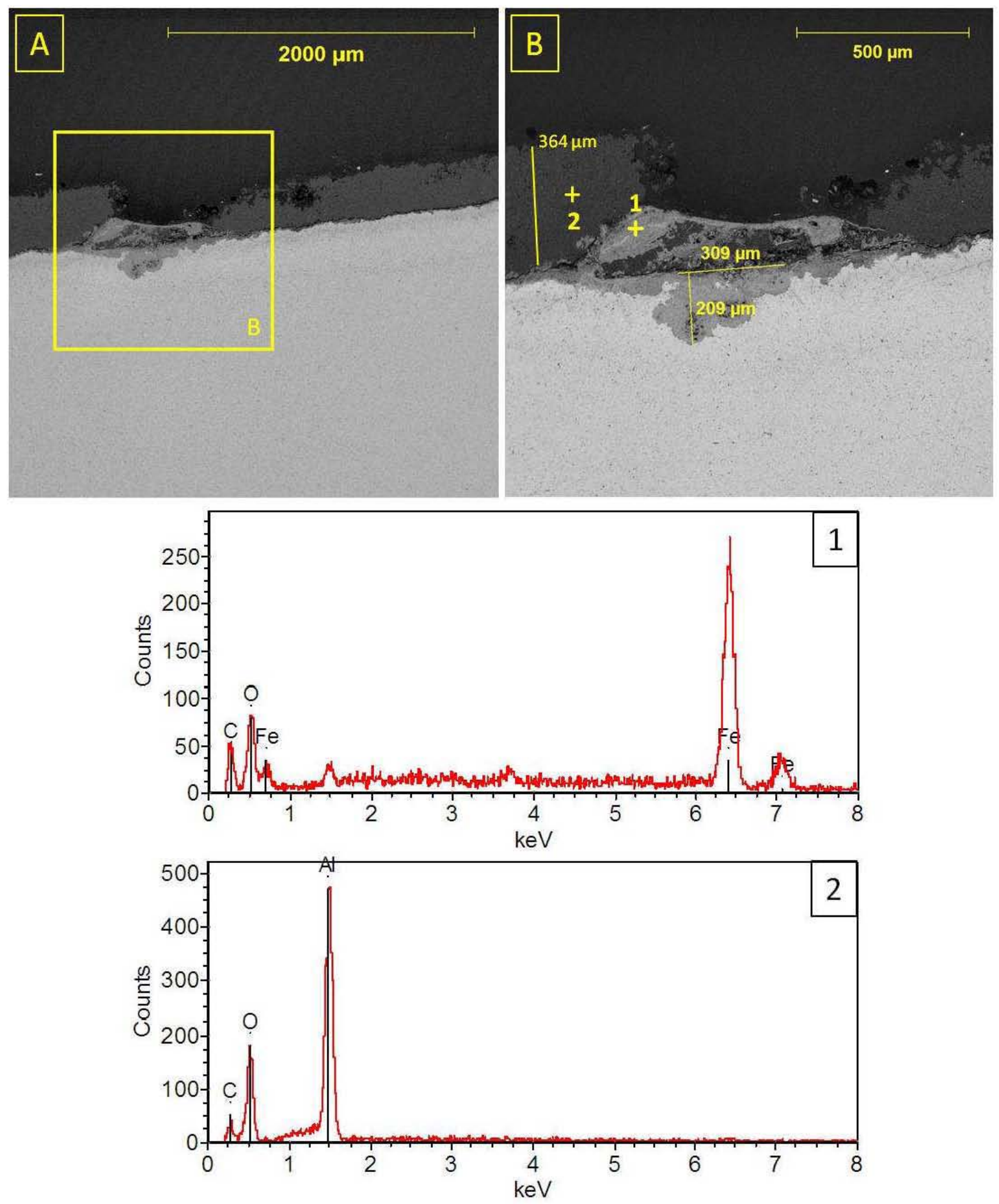


\section{LAB-RPT-12-00007 R0}

The layered carbon, chlorine, and phosphate phase seen in the analysis of the scrapings was also seen in the cross-section analysis. Figure 39 shows this phase as the topmost layer above the aluminum oxide and iron oxide layers.

\section{Figure 39. Scanning Electron Microscopy Image and Energy Dispersive Spectrometry Spectrum of the Carbon and Chlorine-Rich Layer on the Cross-Sectioned Coupon of $\mathrm{SN}-278$.}
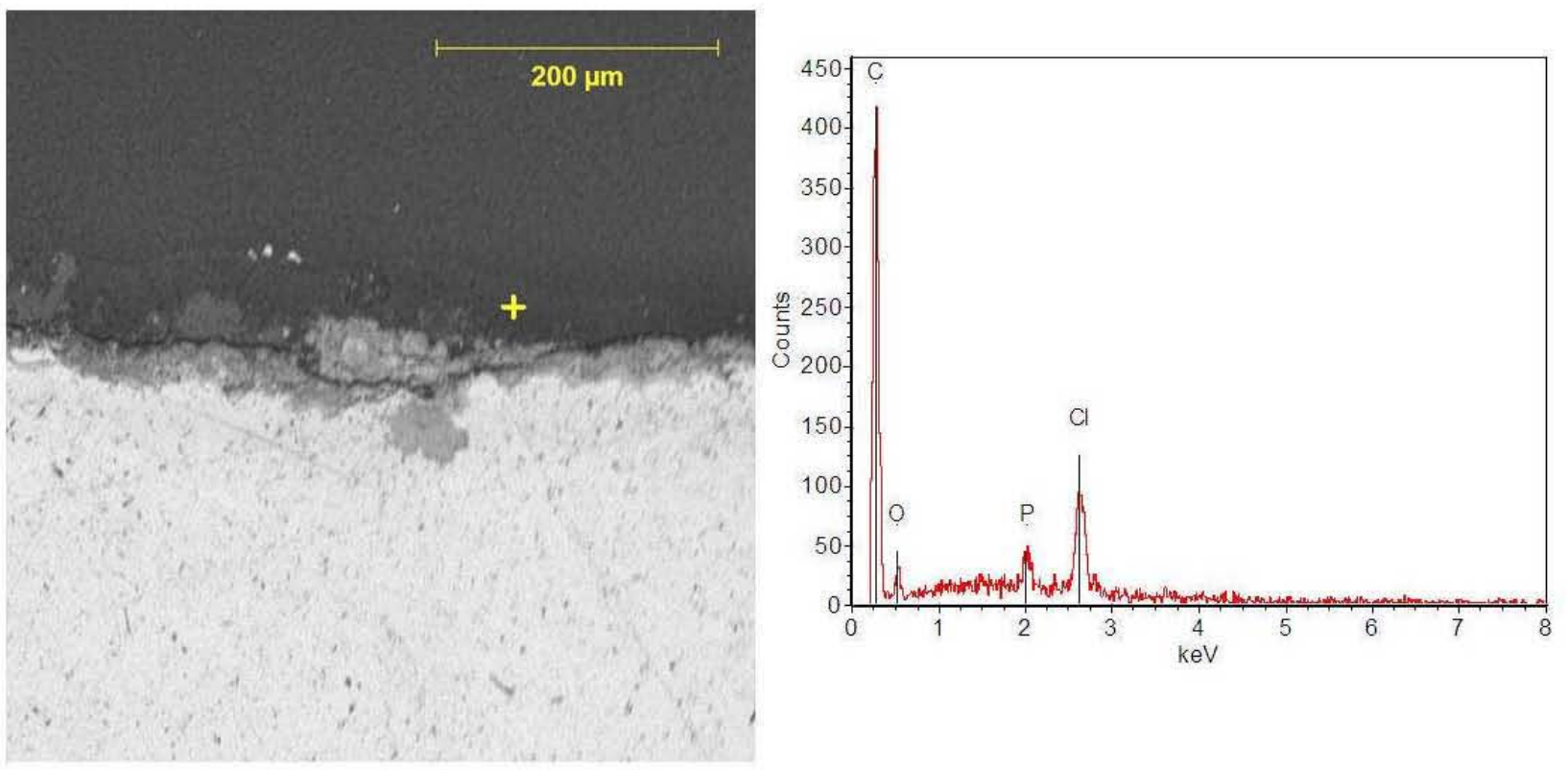

\section{DISCUSSION}

The three primary pipe sections that were examined have several features in common. The UT measurements showed the pipes to have thicknesses that were uniform, averaging about 230 mils and ranging from 210 to 250 mils. This average is within $10 \%$ of the nominal size ( 216 mils), and the spread in values is about $+/-10 \%$ of the average. Pipe SN-278 appears to be the thinnest (averaging 223 mils) and SN-286 the thickest (averaging 236 mils).

All three pipe sections have a layer of material coating the inside of the pipe. This material is largely composed of insoluble tank waste. A similar coating of tank waste was observed inside the 3-in. diameter pipe, SNL-3150, described in 7S110-GAC-05-035. There the coating was found to consist largely of gibbsite and an aluminum and chromium-rich amorphous phase. In the current study, the insoluble tank waste that coats the interior of the pipes is different in the three sections.

Inside the SN-285 3-in. pipe, the tank waste layer is composed of chromium and magnesium with lesser but variable amounts of aluminum, chlorine, calcium, and phosphorous (Figures 10, 


\section{LAB-RPT-12-00007 R0}

13, and 16). Small patches of silver (Figure 14) were also present at many locations on the inner surface.

The coating in SN-286 contains more aluminum than the deposit on the inner wall of SN-285. Lesser amounts of chromium, sodium, calcium, phosphorous, and magnesium are present (see Figures 22-25). Again, silver is part of the tank waste coating the pipe (Figure 25).

SN-278 had an aluminum-rich tank waste coating that included discrete patches of calcium phosphate and minor chromium and other elements (Figures 31 and 34). Discrete patches of silver-rich particulate were not observed associated with the tank waste layer inside the SN-278 3-in. pipe.

There was also evidence of an organic layer occurring in patches on top of the tank waste layer. This material could be remnants of foam. However, in SN-278, the organic layer is rich in phosphorous and chlorine. The foam is not rich in these elements.

Unlike the 3150 stainless steel pipe described in 7S110-GAC-05-035, all three of these pipe sections show evidence for corrosion. Where the layer of tank waste is found, the corrosion layer is between the tank waste and the remaining metal of the pipe. This under-deposit corrosion is patchy, and appears to be most apparent in SN-278 and least apparent in SN-286. In $\mathrm{SN}-278$, pits up to $200 \mu \mathrm{m}$ ( 8 mils) deep and the thickness of the corrosion layer several hundreds of microns thick were observed. In the other two pipe sections, the thickness of corrosion and the depth of pits rarely exceeded $100 \mu \mathrm{m}(4 \mathrm{mils})$ in the cross sections. This corrosion appears to progress by attacking metallic grain boundaries (Figure 34b).

The occurrence of the greatest amount of corrosion in SN-278 may correlate with the UT measurements, where SN-278 was the thinnest of the three pipes on average.

\section{REFERENCES}

7S110-GAC-05-035, 2005, "Final Analytical Results from the Examination of Corrosion on Sections of 244AR Cross-Site Transfer Pipe," (Interoffice Memorandum from Analytical Process Development to R. P. Anantatmula, September 16), CH2MHILL Hanford Group, Inc., Richland, Washington.

ATS-LT-161-100, Rev E-0, "222-S Laboratory Sample Preparation and Operating Procedure for Scanning Electron Microscopes," 2009, Washington River Protection Solutions LLC, Richland, Washington.

LAB-PLN-10-00015, 2011, Test Plan and Procedure for the Corrosion Analysis of Pipeline Sections from Hanford Tank Farms, Rev. 1, Washington River Protection Solutions LLC, Richland, Washington. 


\section{LAB-RPT-12-00007 R0}

LAB-RPT-11-00006, 2011, Final Report for the Corrosion Analysis of SN-285 and SN-286 Pipeline from SY Tank Farm, Rev. 0, Washington River Protection Solutions LLC, Richland, Washington.

RPP-25299, 2007, Volume 4: IQRPE DST System Integrity Assessment-Cathodic Protection for DST Transfer Lines, Rev. 1, CH2M Hill Hanford Group, Inc., Richland, Washington. 
LAB-RPT-12-00007 R0

APPENDIX A

\begin{tabular}{|c|c|c|c|}
\hline$S_{1}$ & $\begin{array}{l}\text { Standards } \\
\text { Calibration }\end{array}$ & $\begin{array}{l}\text { atory } \\
\text { ficate }\end{array}$ & $\begin{array}{c}\text { Kootenai Bldg } 34 \\
\text { MD 1025, PO Box } 968 \\
\text { Richland, WA 99352-0968 } \\
\text { Phone (509) 377- 8444 FAX (509) 377-8219 } \\
\end{array}$ \\
\hline \multicolumn{4}{|l|}{ ASSET INFORMATION } \\
\hline Manufacturer: & SHOP-MADE & Model: & CARBON STEEL \\
\hline Description: & THICKNESS REFERENCE STANDARD & Asset Number: & 584-99-30-155 \\
\hline Report Number: & 584-99-30-155:1343054880 & Serial Number: & 1 \\
\hline Release Number: & NEW & Ref/PO Number: & $12 \mathrm{C} 3007402$ \\
\hline Customer / MD: & AREVA Federal Services, LLC & Building: & 2460 \\
\hline \multicolumn{4}{|c|}{ CALIBRATION INFORMATION } \\
\hline
\end{tabular}

Test Conditions:

\begin{tabular}{|c|c|c|c|c|c|c|}
\hline Receive Date & Calibration Date & Due Date & Temperature & Humidity & Procedure / Revision & Calibration Specification \\
\hline 17-Jul-12 & 23-Jul-12 & 23-Jul-13 & $68 \mathrm{~F}$ & $40 \%$ & SLI 28-284 Rev. 0.0 & Customer \\
\hline
\end{tabular}

Test Results:

\begin{tabular}{|c|c|c|c|c|c|}
\hline Condition & Limited & AS FOUND & AS LEFT & Technician & Remarks \\
\hline PASS & $\mathrm{N}$ & In-Tolerance & In-Tolerance & DA James & See Attached Report w/ Remarks \\
\hline
\end{tabular}

Standards Used for Calibration:

\begin{tabular}{|c|c|c|c|c|c|}
\hline Asset Number & Manufacturer & Model & Description & Cal. Date & Due Date \\
\hline 0065751 & FLUKE & $2626-S$ & THERMO-HYGROMETER PROBE & 31-Aug-11 & 31-Aug-12 \\
\hline $\mathrm{C} 019012$ & HEWLETT PACKARD & $5528 \mathrm{~A}$ & LASER MEASUREMENT SYSTEM & 26-Sep-11 & 2-May-13 \\
\hline
\end{tabular}

Notes/General Conditions:

The calibration program of the Energy Northwest Standards Laboratory is accredited by the American Association of Laboratory Accreditation (A2LA) to ANSI/NCSL Z-540-1-1994 and ANS/ISO/IEC 17025:2005, and complies with the requirements of 10 CFR50 Appendix B, ASME NQA-1 (1989) \& (2000), and the Energy Northwest Standards Laboratory Quality Manual, QM-1 Rev. 9 (1 October 2010).

The standards used in this calibration as described above, and their associated uncertainties or tolerances, are traceable to the National Institute of Standards and Technology (NIST), International System of Units (SI), accepted intrinsic standards, or ratio type measurements. The total uncertainties or tolerances of the standards used are no greater than $25 \%$ of the tolerance of the unit tested, unless otherwise noted. This Report may not be reproduced, except in full, without the permissiop of the Energy Northyest Standards Laboratory. The results stated in this report relate only to item identified in the Asset Information part of this report. 
LAB-RPT-12-00007 R0

APPENDIX B

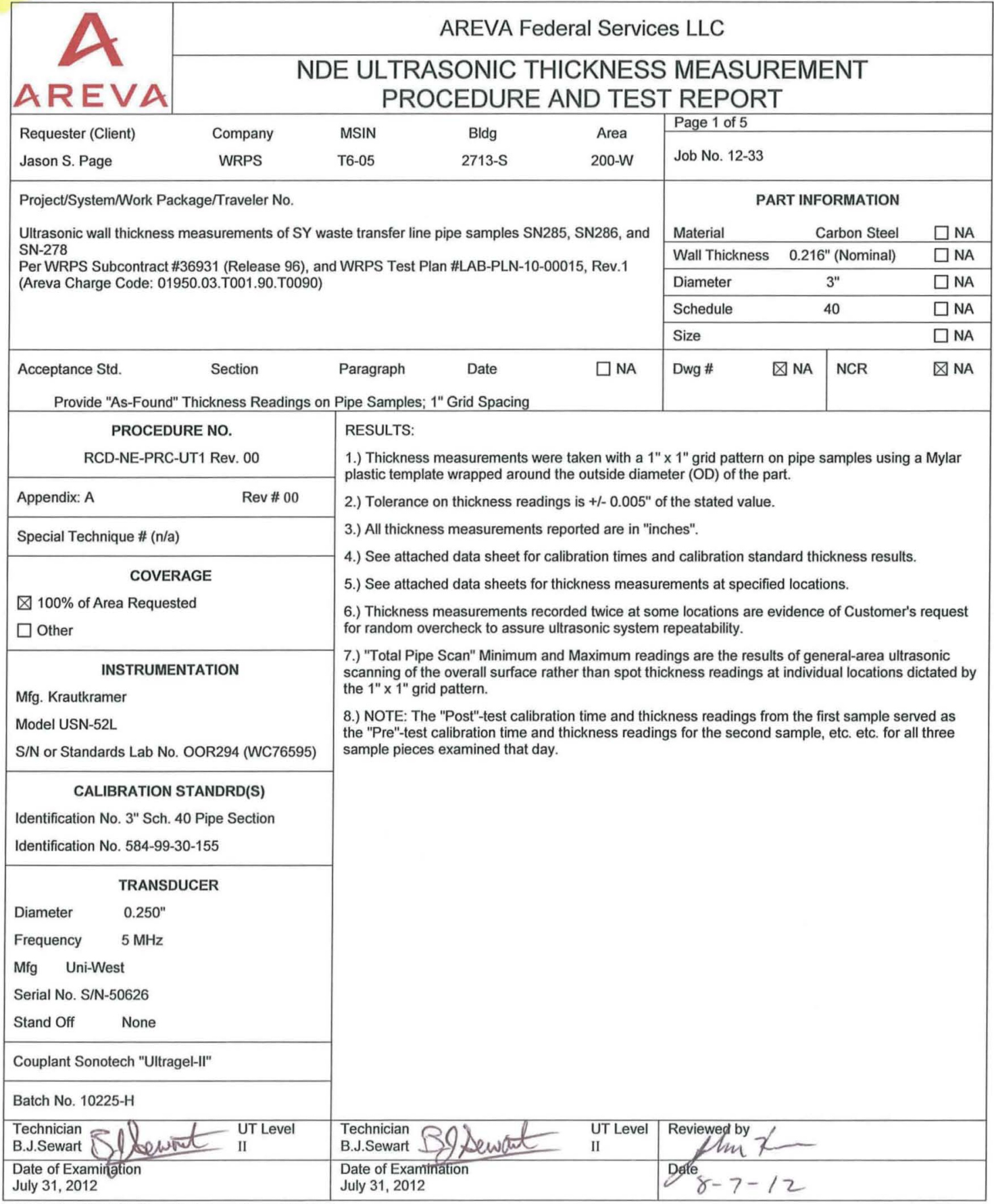

RCD-NE-FRM-005 Rev. 00 (Issued April 17, 2009)

Refer to RCD-NE-PRC-UT1, Ultrasonic Examination 


\section{LAB-RPT-12-00007 R0}

\begin{tabular}{|c|c|}
\hline Callbration Verification Sheet for UT Measurements & 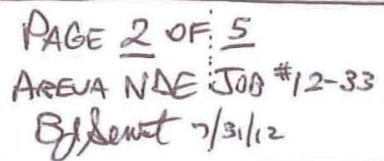 \\
\hline
\end{tabular}

Calibration Block Certification \#: $584 \cdot 99 \cdot 30 \cdot 155$

Date: $d 3 \cdot 3 u / \cdot 13$

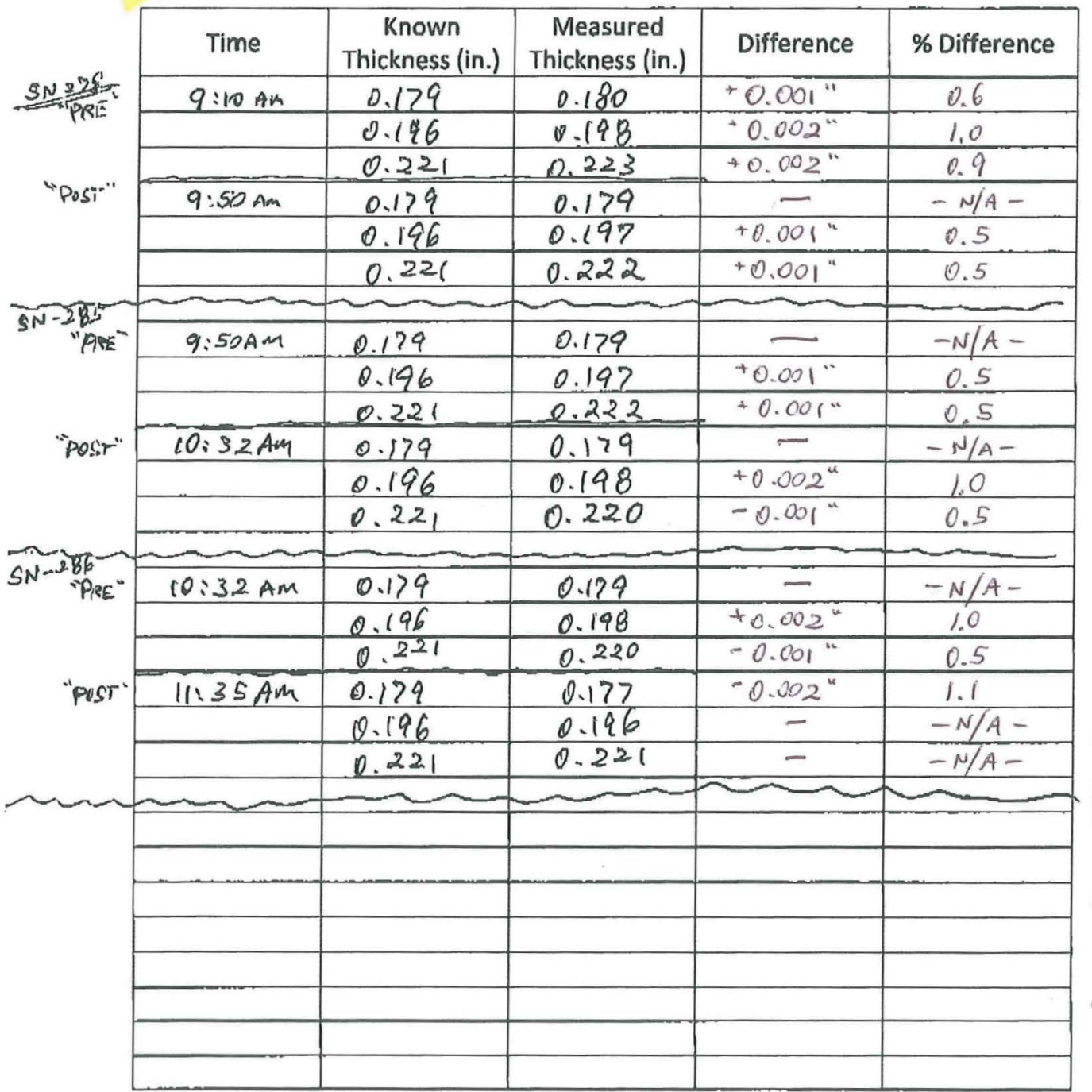




\section{LAB-RPT-12-00007 R0}

Bench Sheet for UT Measurements on SY Transfer PIpe Sections

PABE 3 OF 5

AREVA NDE JaB \#/2-33

Bjolewiont $7 / 31 / 12$.

Sample H: SIIRO00256 Project: $S N 278$

Name(s): J Jason Pags + Brad Sewert Date: 7/31/2an

\begin{tabular}{|c|c|c|c|c|c|c|}
\hline $\begin{array}{l}\text { Template } \\
\text { Labels }\end{array}$ & 1 & 2 & 3 & 4 & 5 & 6 \\
\hline$A$ & 0.225 & 0.230 & 0.224 & 0.231 & $N / A$ & $N / A$ \\
\hline$B$ & 0.235 & 0.230 & $\begin{array}{l}0.231 \\
0.231\end{array}$ & 0.225 & $N / A$ & $N / A$ \\
\hline$C$ & 0.228 & 0.224 & 0.225 & 0.220 & $N / A$ & $N / A$ \\
\hline$D$ & $\begin{array}{c}0.222 \\
0.222\end{array}$ & 0.235 & 0.223 & 0.222 & $N / A$ & $N / A$ \\
\hline$E$ & 0.222 & $\begin{array}{l}\text { HOLE } \\
\text { IN Pire } \\
\text { SAMPLE }\end{array}$ & 0.220 & 0.229 & $N / A$ & $N / A$ \\
\hline$F$ & 0.215 & 0.215 & 0.219 & 0.219 & $N / A$ & $N / A$ \\
\hline$G$ & 0.224 & 0.223 & 0.223 & 0.225 & $N / A$ & $N / A$ \\
\hline$H$ & 0.216 & 0.219 & 0.218 & $\begin{array}{c}0.219 \\
0.220\end{array}$ & $N / A$ & $N / A$ \\
\hline$I$ & 0.219 & 0.210 & 0.215 & 0.216 & $N / A$. & $N / A$ \\
\hline$J$ & 0.227 & 0.223 & 0.225 & 0.222 & $N / A$ & $N / A$ \\
\hline$k$ & 0.223 & 0.220 & 0.219 & 0.219 & $N / A$ & $M / A$ \\
\hline
\end{tabular}

Total Pipe Scan: Minimum 0.211

Maximum 0.233 


\section{LAB-RPT-12-00007 R0}

$07 / 31 / 2012 \quad 1156$ FAX 15093721143

WRPS

(a) Uण I I U 4

PADE 4 OF 5

Bench Sheet for UT Measurements on SY Transfer Pipe Sections AREVA NDE JOE ${ }^{*} / 2-33$

By lewant $7 / 31 / 12$

Sample \#:SIIR000083 Project:SN 285 INNER PIPE

Name(s): Jasun Page + Bred Sewart Date: 7/31/12

\begin{tabular}{||c|c|c|c|c|c|c|}
\hline $\begin{array}{c}\text { Template } \\
\text { Labels }\end{array}$ & 1 & 2 & 3 & 4 & 5 & 6 \\
\hline$A$ & 0.219 & 0.222 & 0.222 & 0.226 & 0.227 & $\mathrm{~N} / \mathrm{A}$ \\
\hline$B$ & 0.229 & 0.234 & 0.234 & 0.237 & 0.235 & $\mathrm{~N} / \mathrm{A}$ \\
\hline$C$ & 0.234 & 0.239 & 0.236 & 0.235 & 0.234 & $\mathrm{~N} / \mathrm{A}$ \\
\hline$D$ & 0.226 & 0.223 & 0.221 & 0.221 & 0.227 & $\mathrm{~N} / \mathrm{A}$ \\
\hline$E$ & 0.232 & 0.230 & 0.227 & 0.230 & 0.228 & $\mathrm{~N} / \mathrm{A}$ \\
\hline$F$ & 0.236 & 0.233 & 0.231 & 0.231 & 0.231 & $\mathrm{~N} / \mathrm{A}$ \\
\hline$G$ & 0.231 & 0.222 & 0.224 & 0.222 & 0.224 & $\mathrm{~N} / \mathrm{A}$ \\
\hline$H$ & 0.228 & 0.226 & 0.231 & 0.231 & $\begin{array}{c}\text { HoteI } \\
\text { PsimA }\end{array}$ & $\mathrm{N} / \mathrm{A}$ \\
\hline$I$ & 0.235 & 0.234 & 0.238 & 0.235 & 0.232 & $\mathrm{~N} / \mathrm{A}$ \\
\hline$J$ & 0.219 & 0.220 & 0.219 & 0.219 & 0.213 & $\mathrm{~N} / \mathrm{A}$ \\
\hline$K$ & 0.221 & 0.222 & 0.227 & 0.224 & 0.221 & $\mathrm{~N} / \mathrm{A}$ \\
\hline
\end{tabular}

Total Pipe Scan: Minimum 0.213

Maximum 0.234 
LAB-RPT-12-00007 R0

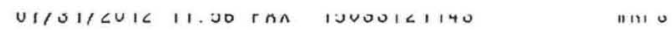

PABE $\underline{S}$ OF $\underline{5}$

Bench Sheet for UT Measurements on SY Transfer Pipe Sections AREVA NDE JO8 $\# 12-33$

B. S demant $7 / 31 / 12$

Sample \#: SIIR 000085 Project: SN 286

Name(s):_Jasun. Page \& Bead Sewoot Date: $7 / 31 / 12$

\begin{tabular}{||l||c|c|c|c|c|c||}
\hline $\begin{array}{c}\text { Template } \\
\text { Labels }\end{array}$ & 1 & 2 & 3 & 4 & 5 & 6 \\
\hline$A$ & 0.241 & 0.237 & 0.238 & 0.244 & 0.234 & 0.233 \\
\hline$B$ & 0.230 & 0.230 & 0.228 & 0.230 & 0.226 & 0.228 \\
\hline$C$ & 0.240 & 0.234 & 0.238 & 0.234 & 0.237 & 0.232 \\
\hline$D$ & 0.237 & 0.236 & 0.238 & 0.235 & 0.236 & 0.235 \\
\hline$E$ & 0.231 & 0.233 & 0.231 & 0.229 & 0.228 & 0.225 \\
\hline$F$ & 0.244 & 0.245 & 0.245 & 0.243 & 0.243 & 0.243 \\
\hline$G$ & 0.240 & 0.240 & 0.242 & 0.240 & 0.237 & 0.239 \\
\hline$H$ & 0.228 & 0.230 & 0.225 & 0.231 & 0.228 & 0.236 \\
\hline$I$ & 0.241 & 0.240 & 0.236 & 0.237 & 0.234 & 0.234 \\
\hline$J$ & 0.246 & 0.241 & 0.234 & 0.234 & 0.232 & 0.240 \\
\hline$K$ & 0.241 & 0.241 & 0.232 & 0.238 & 0.240 & 0.239 \\
\hline \hline
\end{tabular}

Total Pipe Scan: Minimum 0.225

Maximum 0.244 


\section{Electronically Approved by:}

UserName: Page, Jason (h2841343)

Title:

Date: Wednesday, 26 September 2012, 01:30 PM Pacific Time Meaning: Approved by the author or delegate

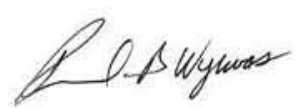

UserName: Wyrwas, Richard (h3390899)

Title: APD Chemist

Date: Wednesday, 26 September 2012, 02:32 PM Pacific Time Meaning: Additional approval obtained

UserName: Cooke, Gary (h0410221)

Title: APD Chemist

Date: Thursday, 27 September 2012, 06:23 AM Pacific Time Meaning: Additional approval obtained

UserName: Castleberry, Jim (h0051558)

Title:

Date: Thursday, 27 September 2012, 07:28 AM Pacific Time Meaning: Approved by the customer or delegate

UserName: Hardy, Don (h0085161)

Title: Laboratory Facilities Manager

Date: Monday, 01 October 2012, 09:38 AM Pacific Time

Meaning: Approved by the Facility Manager or delegate 


\section{Electronically Approved by:}

UserName: Seidel, Cary (h0009079)

Title: APD Manager

Date: Monday, 01 October 2012, 01:49 PM Pacific Time

Meaning: Approved by the Group Manager or delegate 